\title{
Dyslipidemia alters sperm maturation and capacitation in LXR-null mice
}

\author{
M Whitfield ${ }^{1}$, R Guiton ${ }^{1}$, J Rispal ${ }^{1}$, N Acar ${ }^{2}$, A Kocer ${ }^{1}$, J R Drevet ${ }^{1}$ and F Saez ${ }^{1}$ \\ ${ }^{1}$ Team MEPTI (Mécanismes Post-Testiculaires de I'Infertilité), Université Clermont Auvergne, UMR GReD \\ (Génétique Reproduction \& Développement), CNRS 6293, INSERM U1103, Clermont-Ferrand, France and ${ }^{2}$ Centre \\ des Sciences du Goût et de l'Alimentation, AgroSup Dijon, CNRS, INRA, Université Bourgogne Franche-Comté, \\ F-21000 Dijon, France
}

Correspondence should be addressed to J R Drevet or F Saez; Email: joel.drevet@uca.fr or fabrice.saez@uca.fr

\begin{abstract}
Lipid metabolism disorders (dyslipidemia) are causes of male infertility, but little is known about their impact on male gametes when considering post-testicular maturation events, given that studies concentrate most often on endocrine dysfunctions and testicular consequences. In this study, three-month-old wild-type (wt) and Liver-X-Receptors knock out (Lxr $\left.\alpha ; \beta^{-/-}\right)$males were fed four weeks with a control or a lipid-enriched diet containing $1.25 \%$ cholesterol (high cholesterol diet (HCD)). The HCD triggered a dyslipidemia leading to sperm post-testicular alterations and infertility. Sperm lipids were analyzed by LC-MS and those from $L x r \alpha ; \beta^{-/-}$males fed the HCD showed higher chol/PL and PC/PE ratios compared to $w t-\mathrm{HCD}(P<0.05)$ and lower oxysterol contents compared to wt $(P<0.05)$ or $L x r \alpha ; \beta^{-/-}(P<0.05)$. These modifications impaired membrane-associated events triggering the tyrosine phosphorylation normally occurring during the capacitation process, as shown by phosphotyrosine Western blots. Using flow cytometry, we showed that a smaller subpopulation of spermatozoa from $L x r \alpha ; \beta^{-1-}$-HCD males could raise their membrane fluidity during capacitation $(P<0.05$ vs $w t$ or $w t-H C D)$ as well as their intracellular calcium concentration $\left(P<0.05\right.$ vs $L x r \alpha ; \beta^{-/-}$and $P<0.001$ vs wt $)$. The accumulation of the major sperm calcium efflux pump (PMCA4) was decreased in $L x r \alpha ; \beta^{-/-}$males fed the HCD $\left(P<0.05\right.$ vs $L x r \alpha ; \beta^{-/-}$ and $P<0.001$ vs $w t)$. This study is the first showing an impact of dyslipidemia on post-testicular sperm maturation with consequences on the capacitation signaling cascade. It may lead to the identification of fertility prognostic markers in this pathophysiological situation, which could help clinicians to better understand male infertilities which are thus far classified as idiopathic.

Reproduction (2017) 154 827-842
\end{abstract}

\section{Introduction}

Lipid metabolism disorders (dyslipidemia) have dramatically increased around the world in the last decades, with major effects on health and life expectancy. Among dyslipidemia, hypercholesterolemia affects, for example, more than 30 million Americans who are over the age 20 (13.1\% of this population) and present a high blood cholesterol level $(>240 \mathrm{mg} / \mathrm{dL}$, (Mozaffarian et al. 2015)). Other studies have shown a high prevalence of dyslipidemia in the adult population: again, as an example, $45.3 \%$ of French men aged 30-54 years are dyslipidemic without being treated, while only $9.4 \%$ of men in this age group are diagnosed and treated (Ferrieres 2008); similarly in Canada, 43\% of men over age 20 are also presenting a dyslipidemia (Joffres et al. 2013). Even though the negative impact of these diseases on reproductive function is known, very few mechanistic studies on spermatozoa have been published (Whitfield et al. 2015).

Liver-X-Receptors $\alpha$ (LXR $\alpha-N r 1 h 3)$ and $\beta$ (LXR $\beta-$ Nr1h2) are nuclear receptors activated by oxysterols and act as major regulators of cholesterol homeostasis in various cell types (reviewed by Maqdasy et al. (2016)). The importance of LXRs in the male reproductive physiology was underlined by the $L x r \alpha ; \beta^{-/-}$mouse model in which male mice showed infertility starting at five months evolving in sterility at 10 months (Volle et al. 2007). This phenotype was composite, with alterations of both testis (Volle et al. 2007) and epididymis (Frenoux et al. 2004, Ouvrier et al. 2009, Whitfield et al. 2016). We previously showed that the epididymal phenotype could be triggered in young $L x r \alpha ; \beta^{-/-}$animals by an isocaloric high cholesterol diet (HCD) even though the testis showed no structural and functional alterations (Ouvrier et al. 2011). This study revealed the peculiar susceptibility of the epididymis to cholesterol overload and provided a new model of infertility issued from diet-induced hypercholesterolemia. A link between LXR gene polymorphisms and obesity has previously been described in humans (Solaas et al. 2010), suggesting a possible link with male infertility; future studies will be necessary to investigate this point. 
In this model, the HCD-induced epididymal alterations appeared to affect male gamete functions, in complete agreement with the roles played by epididymal maturation in the acquisition of spermfertilizing ability (Cornwall 2009). It is well known that epididymal maturation extensively modifies the sperm protein, sugar and lipid contents (Dacheux et al. 2003). Regarding membranous lipids, sterols and phospholipids are qualitatively and quantitatively modified in order to prepare spermatozoa for the subsequent events of sperm post-testicular maturation (i.e. capacitation and acrosomal reaction). In mice, a decrease in the sperm cholesterol content was observed during epididymal transit (Rejraji et al. 2006).

Capacitation was defined in the early 1950 s as a set of functional and biochemical events that occur after ejaculation in the female genital tract (Chang 1951, Austin 1952). Capacitation is triggered by plasma membrane cholesterol loss (Travis \& Kopf 2002) toward cholesterol acceptors in the female secretions (Visconti et al. 1999). Recent studies have described the participation of oxysterol (cholesterol oxidation products) production during the course of capacitation as facilitating sterol efflux to further increase membrane fluidity (Brouwers et al. 2011, Boerke et al. 2013). Consequently, sperm plasma membrane fluidity is increased, allowing the activation of ion channels. Intracellular $\mathrm{pH}\left(\mathrm{pH}_{\mathrm{i}}\right)$ (Chavez et al. 2012) and intracellular calcium concentration $\left(\left[\mathrm{Ca}^{2+}\right]_{\mathrm{i}}\right)$ are increased (Lishko et al. 2012), leading to the activation of an intracellular signaling cascade via a rise in cAMP intracellular concentration produced by the soluble adenylyl cyclase sAC (Wertheimer et al. 2013). The Ser/Thr kinase PKA (protein kinase A) is consequently activated by CAMP resulting in phosphorylation of numerous targets. Tyrosine kinases are activated, which will in turn phosphorylate specific tyrosine residues on sperm proteins (Visconti et al. 1995). Ultimately, gametes acquire a hyperactive motility (Nassar et al. 1999) and the ability to bind and fertilize an oocyte.

Based on our mouse model of $L x r \alpha ; \beta^{-/-}$males fed for four weeks with an HCD, this work investigates the impact of the dyslipidemia-induced epididymal disruption on sperm post-testicular lipid composition and maturation, especially during the in vitro capacitation process.

\section{Materials and methods}

\section{Animals}

Mice $\left(L x r \alpha ; \beta^{-/}\right.$and $\left.w t\right)$ were derived from a mixed strain background (C57BL/6:129Sv) and were housed in an animal facility with a controlled environment $\left(22^{\circ} \mathrm{C}, 12 \mathrm{~h}\right.$ light $/ 12 \mathrm{~h}$ dark). Control mice were fed ad libitum with a Global-diet 2016 (Harlan, Gannat, France). Under HCD, three-monthold males were fed for four weeks with a lipid-enriched diet containing $1.25 \%$ cholesterol (Safe, Augy, France). Mouse housing and manipulations were approved by the Regional
Ethic Committee in Animal Experimentation (authorization CE 100-12). Mice were killed by cervical dislocation.

\section{Sperm collection}

For all experiments, sperm were collected by pressure on cauda epididymis in $1.0 \mathrm{~mL}$ of non-capacitating $\mathrm{WH}$ medium (see composition later) and then counted using a Malassez hemocytometer.

\section{Cholesterol and phospholipids assays}

Cholesterol and phospholipids assays were carried out at the MetaToul platform (Toulouse). Lipids of sperm (four million) from $w t$, wt-HCD, $L x r \alpha ; \beta^{-/-}$and $L x r \alpha ; \beta^{-/-}$HCD were extracted by the Bligh and Dyer method (Bligh \& Dyer 1959) with internal standard. Regarding phospholipids, the calibration range was performed for each compound, and then extracts and range were analyzed by liquid chromatography (LC-ESIQqQ 6460 Agilent). Sterols were silylated and then analyzed by gas chromatography (GC-MS simple quadrupole).

\section{Oxysterols assay}

Total lipids were extracted from a pool of six million spermatozoa according to the method of Folch et al. (1957). Oxysterols were quantified by gas chromatography coupled to mass spectrometry according to previously published procedures (Grandgirard et al. 2004, Fourgeux et al. 2012). After a known quantity of betulin (Sigma-Aldrich) was added as an internal standard, samples were submitted to alkaline hydrolysis in $\mathrm{KOH}$ before oxysterols were extracted with dichloromethane. Oxysterols were purified on silica columns with acetone and derivatized into trimethylsilyl ethers by the addition of pyridine and BSTFA. Trimethylsilyl ethers were analyzed on a Shimadzu QP2010 gas chromatograph coupled to a mass spectrometer (Shimadzu, Marne-LaVallée, France). Samples were injected in a splitless mode at an injection temperature of $290^{\circ} \mathrm{C}$ on a DB-5MS fused silica capillary column $(30 \mathrm{~m} \times 0.25 \mathrm{~mm}$ i.d., film thickness $0.25 \mu \mathrm{m}$, Agilent Technologies). Hydrogen was used as the carrier gas (inlet pressure $60 \mathrm{kPa}$ ). The flame ionization detector was maintained at $290^{\circ} \mathrm{C}$. The initial oven temperature was held at $50^{\circ} \mathrm{C}$ for one minute, and then increased at a rate of $20^{\circ} \mathrm{C} /$ $\min$ to $250^{\circ} \mathrm{C}$ and thereafter at $5^{\circ} \mathrm{C} / \mathrm{min}$ to a final temperature of $300^{\circ} \mathrm{C}$. Electron impact ionization was used at $70 \mathrm{eV}$ ionization energy. Oxysterols were analyzed in the single ion monitoring mode at $\mathrm{m} / \mathrm{z} 456$ for $7 \alpha$-hydroxycholesterol and $7 \beta$-hydroxycholesterol, at $\mathrm{m} / \mathrm{z} 474, \mathrm{~m} / \mathrm{z} 366$ and $\mathrm{m} / \mathrm{z} 356$ for $\alpha$-epoxycholesterol and $\beta$-epoxycholesterol, at $\mathrm{m} / \mathrm{z} 472$ and $\mathrm{m} / \mathrm{z} 382$ for 7 -ketocholesterol and at $\mathrm{m} / \mathrm{z} 483$ and $\mathrm{m} / \mathrm{z} 496$ for betulin. Absolute amounts of each oxysterol were determined by interpolation from a standard curve of betulin generated for each experiment.

\section{Capacitation media}

The basic medium used throughout these studies for sperm preparation and in vitro capacitation was a modified Krebs- 
Ringer medium (Whitten's-HEPES buffer (WH) containing $100 \mathrm{mM} \mathrm{NaCl}, 4.7 \mathrm{mM} \mathrm{KCl}, 1.2 \mathrm{mM} \mathrm{KH}_{2} \mathrm{PO}_{4}, 1.2 \mathrm{mM} \mathrm{MgSO}_{4}$, $5.5 \mathrm{mM}$ glucose, $1 \mathrm{mM}$ pyruvic acid, $4.8 \mathrm{mM}$ lactic acid, $20 \mathrm{mM}$ HEPES, $\mathrm{pH}$ 7.4). Capacitation medium 1 contained $5 \mathrm{mg} / \mathrm{mL}$ fatty-acid-free BSA (Sigma-Aldrich), $2 \mathrm{mM} \mathrm{CaCl}_{2}$ and $20 \mathrm{mM} \mathrm{NaHCO}_{3}$ in WH. Capacitation medium 2 was made with WH supplemented with $1 \mathrm{mM}$ 8-Bromo-cAMP (Sigma) and $500 \mu \mathrm{M}$ IsoButylMethylXanthine (IBMX, Sigma). For BSA range experiments, capacitation medium 1 was used with increasing fatty-acid-free BSA concentrations (0-0.3-1-3-510-20-30 mg/mL).

\section{Analysis of capacitation by Western blot}

Sperm were incubated in capacitation medium 1 or 2 at the final concentration of $15 \times 10^{6}$ cells $/ \mathrm{mL}$ during 0,45 or $90 \mathrm{~min}$ at $37^{\circ} \mathrm{C}, 5 \% \mathrm{CO}_{2}$. Each time, one million was collected, centrifuged at $500 \mathrm{~g}$ for five minutes, washed with $300 \mu \mathrm{L}$ of phosphate buffered saline (PBS) and then resuspended in sample buffer without mercaptoethanol and boiled for five minutes. After a centrifugation at $7000 \mathrm{~g}$ for five minutes, the supernatant was collected, boiled in the presence of $5 \%$ mercaptoethanol (Sigma) for five minutes and then subjected to SDS-PAGE as described later.

\section{Extraction of sperm proteins}

Cauda epididymal sperm proteins were extracted in RIPA buffer (50 mM Tris, $150 \mathrm{mM} \mathrm{NaCl}, 12 \mathrm{mM}$ sodium deoxycholate, $3 \mathrm{mM}$ sodium dodecyl sulfate, 1\% Igepal CA-630, Sigma) supplemented with protease inhibitors (Complete mini, Roche) and phosphatase inhibitors (Halt phosphatase inhibitor cocktail, ThermoScientific) and subjected to $30 \mathrm{~min}$ of sonication $(30 \mathrm{~s} / 30 \mathrm{~s})$ at $4{ }^{\circ} \mathrm{C}$. Samples were then centrifuged at $14,000 \mathrm{~g}$ for $10 \mathrm{~min}$ at $4^{\circ} \mathrm{C}$. Supernatants were collected and the proteins were dosed by the bicinchoninic acid method. For electrophoresis, $25 \mu \mathrm{g}$ of proteins was diluted in Laemmli sample buffer and incubated for five minutes at $100^{\circ} \mathrm{C}$.

\section{Extraction of tissue proteins}

Testis, caput and cauda epididymal tissues were homogenized in high salt buffer $\left(25 \mathrm{mM}\right.$ HEPES, $0.4 \mathrm{M} \mathrm{NaCl}, 1.5 \mathrm{mM} \mathrm{MgCl}_{2}$, $0.2 \mathrm{mM}$ EDTA, 1\% Igepal CA-630, Sigma) supplemented with protease and phosphatase inhibitors. Lysates were centrifuged at $4^{\circ} \mathrm{C}$ for $10 \mathrm{~min}$ at $13,000 \mathrm{~g}$. Supernatants were collected and the proteins were dosed by the Bradford method. For electrophoresis, $25 \mu \mathrm{g}$ of proteins was diluted in Laemmli sample buffer and incubated for five minutes at $100^{\circ} \mathrm{C}$.

\section{Collection of epididymosomes}

Cauda epididymides from six mice were collected in $500 \mu \mathrm{L}$ of $\mathrm{WH}$. Sperm cells were retrieved in $\mathrm{WH}$ by first stitching tissues using a needle, and sperm suspensions were collected. Then, tissues were minced in $500 \mu \mathrm{L}$ of $\mathrm{WH}$ to release epididymal fluid. Suspensions of tissues and sperm were centrifuged separately at $500 \mathrm{~g}$ for five minutes at $4{ }^{\circ} \mathrm{C}$. The supernatants were further clarified by centrifugation $(16,000 \mathrm{~g}, 20 \mathrm{~min}$ at $4^{\circ} \mathrm{C}$ ) and pooled, representing the epididymal luminal fluid (ELF). Using an Optima L-80 XP centrifuge with SW41 rotor (Beckman Coulter, Roissy CDG, France), the ELF was subjected to ultracentrifugation at $120,000 \mathrm{~g}$ for two hours at $4^{\circ} \mathrm{C}$. The pellet, containing the epididymosomes, was taken up in $25 \mu \mathrm{L}$ RIPA buffer, and the proteins were extracted by $30 \mathrm{~min}$ of sonication as described earlier. Supernatants were collected and the proteins were dosed by the bicinchoninic acid method. For electrophoresis, $25 \mu \mathrm{g}$ of proteins were diluted in Laemmli sample buffer and incubated for five minutes at $100^{\circ} \mathrm{C}$.

\section{Immunoprecipitation of phosphotyrosine- containing proteins}

Cauda epididymal sperm were collected as described earlier, and 80 million sperm cells were incubated in capacitation medium 1. At 0 and $90 \mathrm{~min}$ of incubation, sperm cells (40 million) were washed in PBS, and proteins were extracted in RIPA with protease and phosphatase inhibitors. After sonication as described earlier, lysates were centrifuged at $4{ }^{\circ} \mathrm{C}$ for $10 \mathrm{~min}$ at $15,000 \mathrm{~g}$. Supernatants were incubated $30 \mathrm{~min}$ at $4^{\circ} \mathrm{C}$ with Protein $\mathrm{A} / \mathrm{G}$ magnetic beads (ThermoScientific) for preclearing. Then, $20 \mu \mathrm{L}$ of supernatants was mixed with $5 \mu \mathrm{L}$ of Laemmli $5 \times$ and boiled for five minutes (input). The remainder of the supernatants was subjected to immunoprecipitation by incubation with $20 \mu \mathrm{L}$ of magnetic beads conjugated with the anti-phosphotyrosine antibody (16-282, Merck Millipore), overnight at $4^{\circ} \mathrm{C}$. Then, magnetic beads were washed thrice with $300 \mu \mathrm{L}$ of PBS and boiled for five minutes in $20 \mu \mathrm{L}$ of Laemmli $2 \times$ before SDS-PAGE as described later.

\section{SDS-PAGE and Western blot analysis}

Protein samples were subjected to denaturing SDS-PAGE and transferred on nitrocellulose membrane (Hybond ECL, Amersham Biosciences). Blots were blocked with Tris Buffered Saline $(50 \mathrm{mM}$ Tris, $150 \mathrm{mM} \mathrm{NaCl})$ containing $0.1 \% \mathrm{v} / \mathrm{v}$ Tween 20 and $10 \% \mathrm{w} / \mathrm{v}$ low-fat dried milk for anti-phosphotyrosine (05-321, clone 4G10, Merck Millipore), $\alpha$-Tubulin (T6074, Sigma) and $\beta$-Actin (A2066, Sigma) antibodies, 5\% w/v BSA for VDAC-2 antibody (ab37985, ABCAM) or 5\% w/v low-fat dried milk and 3\% casein for PMCA4 antibody (sc-22080, Santa Cruz Biotechnology). Membranes were probed overnight at $4{ }^{\circ} \mathrm{C}$ with anti-phosphotyrosine (1/1000), $\alpha$-Tubulin (1/10,000), $\beta$-Actin (1/1000), VDAC2 (1/250) and PMCA4 (1/500) antibodies in corresponding blocking solutions. After washing, membranes were incubated with the following secondary antibodies: antimouse horseradish peroxidase-conjugated (HRP) (BI 2413C, $1 / 1000$ for anti-phosphotyrosine and $\alpha$-Tubulin; Abliance, Compiègne, France), anti-rabbit HRP (BI 2407, 1/1000 for $\beta$-Actin, Abliance) and anti-goat HRP (BI 2403, 1/1000 for VDAC2, Abliance). For PMCA4, anti-goat Biotin-SP conjugated (1/5000, 705-066-147, Jackson Immunoresearch) followed by streptavidine HRP (1/5000, 016-030-084, Invitrogen) were used. Detection was performed using the Immobilon Western Chemiluminescent HRP substrate (Millipore) on MF-ChemiBIS 3.2 camera (DNR Bioimaging systems, Jerusalem, Israel), and densitometric analyses were carried out using Multi Gauge v3.2 software. 
Table 1 Sequences of the primers used in quantitative RT-PCR (Reverse Transcription-Polymerase Chain Reaction) experiments.

\begin{tabular}{llllr}
\hline Gene & NCBI reference \# & Forward primer $\left(5^{\prime} \rightarrow 3^{\prime}\right)$ & Reverse primer $\left(5^{\prime} \rightarrow 3^{\prime}\right)$ & Amplicon size $($ bp) \\
\hline 36b4 & NM_007475.5 & gtc act tgt cca gct cag aa & tca atg gtg cct ctg gag at & 98 \\
Pmca4 & NM_001167949.2 & ctg caa ggc aaa ctc aca cg & act cag gaa gcc att ctc gg & 139 \\
Vdac2 & NM_011695.2 & aag acg aag tca tgc agc gg & cgg tgt tcc act tct ctg tga & 139 \\
\hline
\end{tabular}

\section{Evaluation of membrane fluidity using flow cytometry}

Sperm $\left(15 \times 10^{6}\right.$ cells $\left./ \mathrm{mL}\right)$ were incubated in capacitation medium 1 during 0, 45 and $90 \mathrm{~min}$. Each time, after washing in $\mathrm{WH}, 2.7 \mu \mathrm{M}$ of merocyanine 540 (marker of membrane fluidity, Molecular Probes) and $25 \mu \mathrm{M}$ of YO-PRO-1 (a marker of viability, Molecular Probes) were added and $0.5 \times 10^{6}$ sperm cells were acquired in LSR II (BD Biosciences, San Jose, CA, USA) flow cytometer, and the results were analyzed using FACSDIVA 6.01 software.

\section{Determination of calcium flux using flow cytometry}

Cauda epididymal sperm cells $\left(10 \times 10^{6}\right.$ cells $\left./ \mathrm{mL}\right)$ were loaded with $5.0 \mu \mathrm{M}$ of Fluo4-AM probe (dissolved in $20 \%$ Pluronic F127 to facilitate cell loading) for one hour at room temperature in the dark (Molecular Probes) in WH. After washing in $\mathrm{WH}$, sperm were incubated in capacitation medium 1 for 0,45 and $90 \mathrm{~min}$. Before each assay, $1.5 \mu \mathrm{g} / \mathrm{mL}$ of propidium iodide (a marker of cell viability, Sigma) was added and $0.5 \times 10^{6}$ sperm cells were acquired on an LSR II (BD Biosciences) flow cytometer, and the results were analyzed using FACSDIVA 6.01 software.

\section{Immunocytology}

Sperm $\left(5 \times 10^{6}\right.$ cells $\left./ \mathrm{mL}\right)$ were fixed in paraformaldehyde $2 \%$ in PBS for $15 \mathrm{~min}$ at $4^{\circ} \mathrm{C}$. After two washes in PBS, sperm were spread on glass slides. After drying at room temperature, sperm were permeabilized with PBS-triton $0.2 \%$ for $20 \mathrm{~min}$ and blocked one hour with PBS-triton 0.2\%, NGS 1.5\% (normal goat serum, Vector Laboratories, Burlingame, CA, USA). Slides were then probed with anti-phosphotyrosine 4G10 antibody (1/100, Merck Millipore) overnight at $4^{\circ} \mathrm{C}$. The secondary anti-mouse Alexa Fluor 555-conjugated antibody (1/100, A21425, Life Technologies) was incubated one hour at room temperature, and sperm nuclei were stained with Hoechst $33342(1 \mu \mathrm{g} / \mathrm{mL}$, Invitrogen) and mounted on PBS/glycerol. The percentages of unlabeled, tail, head and head + tail stains were evaluated by counting at least 200 cells per slide.

\section{Quantification of mRNA by Real-Time Quantitative RT-PCR}

Total mRNAs from testis, caput and cauda epididymides were isolated using the NucleoSpin RNA II column kit (MachereyNagel, Düren, Germany), according to manufacturer's instructions. RNA $(1 \mu \mathrm{g})$ was reverse-transcribed, and quantitative PCR was performed as previously described (Whitfield et al. 2016). The relative accumulation level of each mRNA was normalized using $36 \mathrm{~b} 4$ as a standard and analyzed with the $\Delta \Delta \mathrm{Ct}$ method. Primer sequences are listed in Table 1.

\section{Results}

\section{Dyslipidemia affects sperm lipid composition}

To test whether the diet-induced epididymal phenotype affects the sperm lipid content, we assayed the cholesterol and phospholipid composition in cauda epididymal sperm of four-month-old $w t$ or $L x r \alpha ; \beta^{-/-}$ male mice fed a control or HCD diet. No significant difference in cholesterol or total phospholipids was apparent between groups (Fig. 1A). However, the cholesterol/phospholipid (Chol/PL) ratio and the phosphatidylethanolamine/phosphatidylcholine (PE/PC) ratio were significantly increased in sperm from Lxr $\alpha ; \beta^{-1-}$-HCD mice $(P<0.05$ compared to $w t$-HCD, Fig. 1A). As recent articles have described the presence of oxysterols in sperm (Brouwers et al. 2011, Boerke et al. 2013) thought to promote membrane fluidity by causing lateral membrane expansion (Olkkonen \& Hynynen 2009), we assessed the amount of oxysterols in cauda sperm cells by mass spectrometry. Total oxysterols were significantly decreased in $L x r \alpha ; \beta^{-/-}-H C D$ compared to wt and $L x r \alpha ; \beta^{-1-}$, mainly due to a decrease in $7 \alpha$-hydroxycholesterol, $\quad 7 \beta$-hydroxycholesterol, 7-ketocholesterol and $\beta$-epoxycholesterol $\quad(P<0.05$ compared to $w t$ and $L x r \alpha ; \beta^{-l-}$, Fig. $\left.1 \mathrm{~B}\right)$. Overall, these data suggest that dyslipidemia disrupts the epididymal function and impairs sperm lipid composition in $L x r \alpha ; \beta^{-/-}$males fed with the HCD.

\section{Dyslipidemia disrupts membrane-related capacitation events}

Cholesterol efflux from the sperm plasma membrane facilitated by acceptors such as albumin present in the secretions of the female genital tract triggers sperm capacitation. This can be mimicked in vitro by adding BSA in the capacitation medium (Fig. 2A-1), and the efficiency of capacitation can be measured by quantifying tyrosine-phosphorylated proteins by Western blot, as it is a final marker of the process.

As shown in Fig. 2A1, the HCD had no effect on capacitation efficiency in wt animals, during a kinetic study between 0, 45 and 90 min of incubation. Lxr $\alpha ; \beta^{-/-}$ males showed a rather altered tyrosine phosphorylation profile that was slightly aggravated by the HCD. Since signaling pathway following sperm plasma membrane cholesterol efflux involves sAC-mediated cAMP production, which in turns activates PKA resulting in fine in tyrosine phosphorylation events, we have used 8-bromocAMP (a cell-permeant analog of cAMP) and IBMX (an 
A
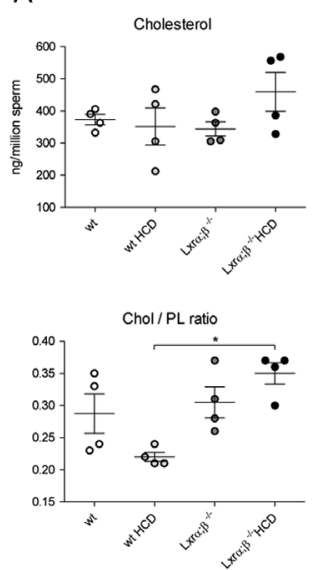
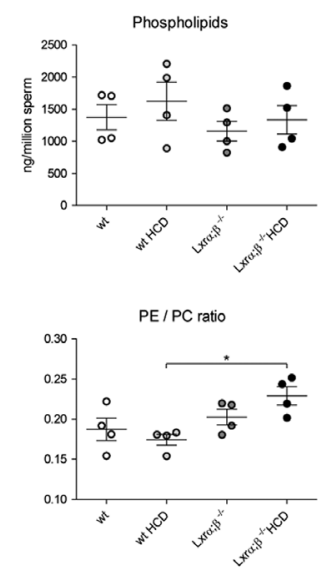

B
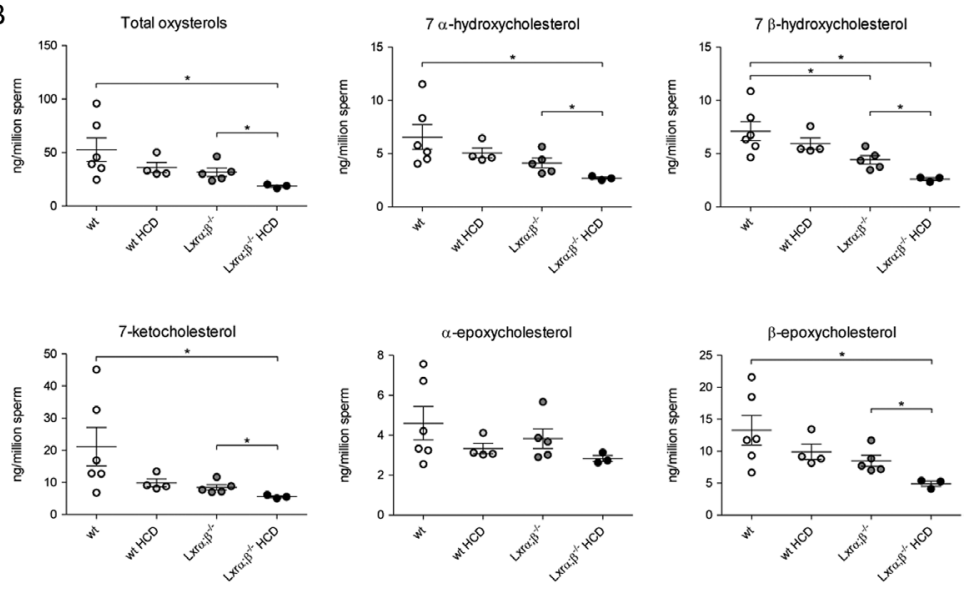

Figure 1 Influence of HCD on sperm lipid composition. (A) Cholesterol and phospholipids were assayed and membrane-fluidity-related ratios were calculated on sperm from control diet- and HCD-fed four-month-old wild-type $(w t)$ and $L x r \alpha ; \beta^{-/-}$mice. Horizontal bars represent means \pm S.E.M., $n=4$. (B) Total and different classes of oxysterols were assayed from sperm of control and HCD-fed four-month-old wild-type (wt) and $L x r \alpha ; \beta^{-/-}$mice. Horizontal bars represent means \pm S.E.M., $n=6 w t, 4 w t-H C D, 5 L x r \alpha ; \beta^{-/-}, 3 L x r \alpha ; \beta^{-/-}$HCD. ${ }^{*} P<0.05$ between the compared groups (Mann-Whitney test). Chol, cholesterol; PL, phospholipids; PE, phosphatidylethanolamine; PC, phosphatidylcholine.

inhibitor of the phosphodiesterases responsible for cAMP degradation) to produce an increase in intracellular cAMP. In doing so, PKA is activated independently of the physiological membrane events (cholesterol efflux) normally triggering the capacitation process. Under these conditions (Fig. 2A-2), tyrosine phosphorylation of sperm proteins during capacitation was similar between groups. This result strongly suggests that the dysregulations observed with BSA as a capacitation inducer are due to membrane defaults, upstream of cAMP production. This hypothesis was further tested by incubating sperm in capacitation media containing increasing amounts of BSA (Fig. 2B). For wt sperm, fed with control diet or HCD, the maximum efficiency was reached when low concentrations of BSA were present (left and right upper panels). Maximum efficiency in tyrosine phosphorylation was reached with higher BSA concentrations for $L x r \alpha ; \beta^{-1-}$ males (lower left panel) and Lxr $\alpha ; \beta^{-/-}$-HCD males (lower right panel). These results are in accordance with changes in membrane dynamics limiting cholesterol efflux to extracellular acceptors, and thus altering capacitation efficiency.

To determine if the decrease in tyrosine phosphorylation was due to a decrease in the number of capacitating sperm cells or to a decrease in the overall phosphorylation intensity, the percentage of sperm cells stained by the anti-phosphotyrosine antibody was calculated (Fig. 3A). It clearly appeared that significantly fewer spermatozoa were stained in the $L x r \alpha ; \beta^{-/}$males compared to the wt group at any time of capacitation (a). These results also showed that sperm from $L x r \alpha ; \beta^{-{ }^{-}-}$ HCD mice were significantly less stained than the ones from $L x r \alpha ; \beta^{-/-}$males (c), here again in accordance with the Western blot data. At t0, fewer wt-HCD spermatozoa were stained compared to $w t$, but this difference was not maintained during the course of capacitation. The defects in the capacitation-associated signaling pathway were probably located on the whole sperm cell surface as the percentages of sperm cells stained on the head or the tail were lower in the $L x r \alpha ; \beta^{-/-}$males fed or not with the HCD compared to the wt groups at any time of capacitation (Fig. 3B).

\section{Dyslipidemia alters sperm membrane fluidity during capacitation}

Sperm plasma membrane fluidity was evaluated using a direct method with merocyanine-540 (M-540) that has the ability to target membrane fluid domains. M-540 detection was coupled with YO-PRO-1 (detecting live cells), and flow cytometry was used to measure the relative proportion of live sperm undergoing membrane fluidification during the capacitation process. In Fig. 4A, living spermatozoa (in green in the Q4 quartile) appeared as separated into two subpopulations (P2 and P3): P2 showing low membrane fluidity and P3 showing high membrane fluidity. During the course of capacitation, the relative proportion of the P3 subpopulation increased, revealing an increase in the percentage of sperm cells showing high fluidity (lower panel of Fig. 4A). When comparing the percentages of sperm cells in the P3 subpopulation between groups, there was no significant difference at t0 (Fig. 4B, left panel). At that time, the heterogeneity was high, and a tendency to a lower membrane fluidity was visible for $L x r \alpha ; \beta^{--}$males fed the normal diet or the HCD. During capacitation, at 445 and t90, significantly fewer spermatozoa reached a state of high membrane fluidity for the $L x r \alpha ; \beta^{-/-}$males fed with the HCD compared to $w t$ and $w t-\mathrm{HCD}$ spermatozoa (Fig. 4B, middle and right 
A

(1)
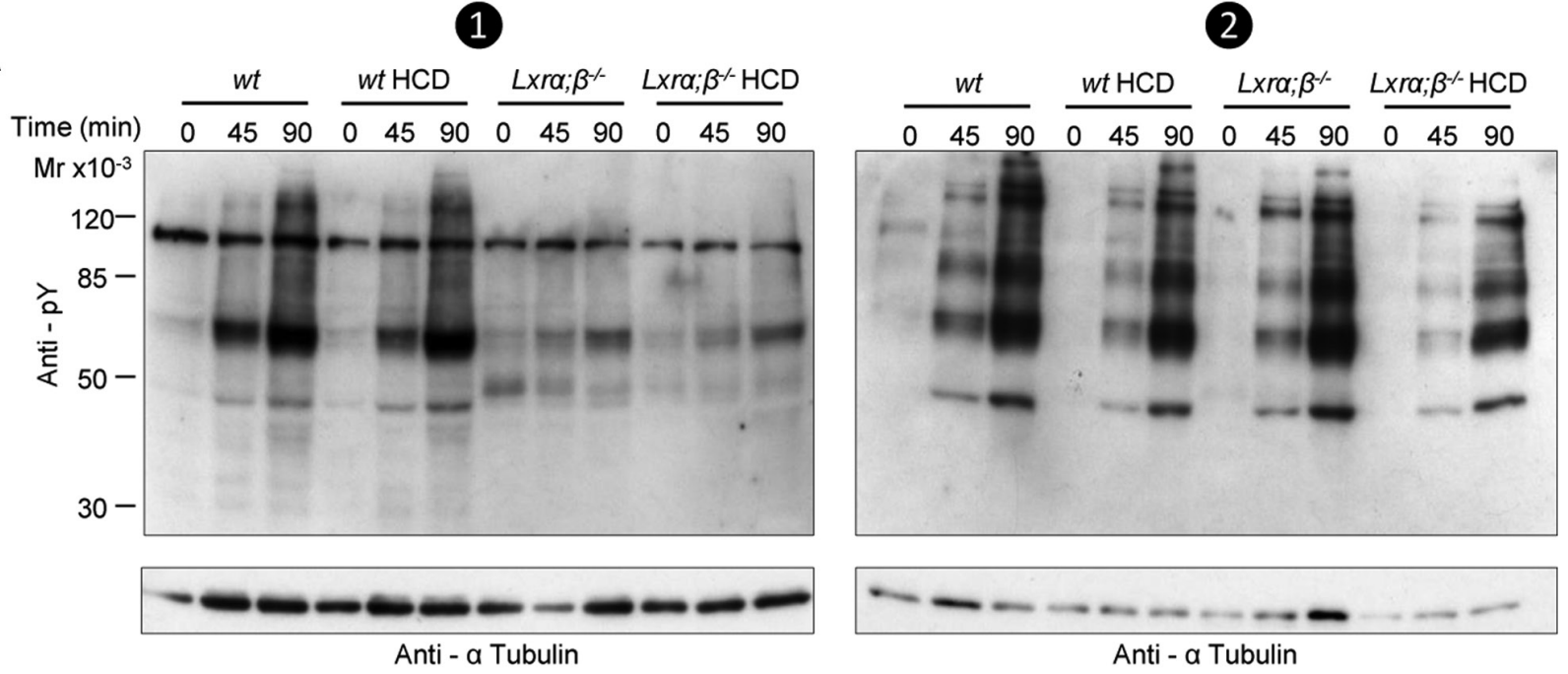

B
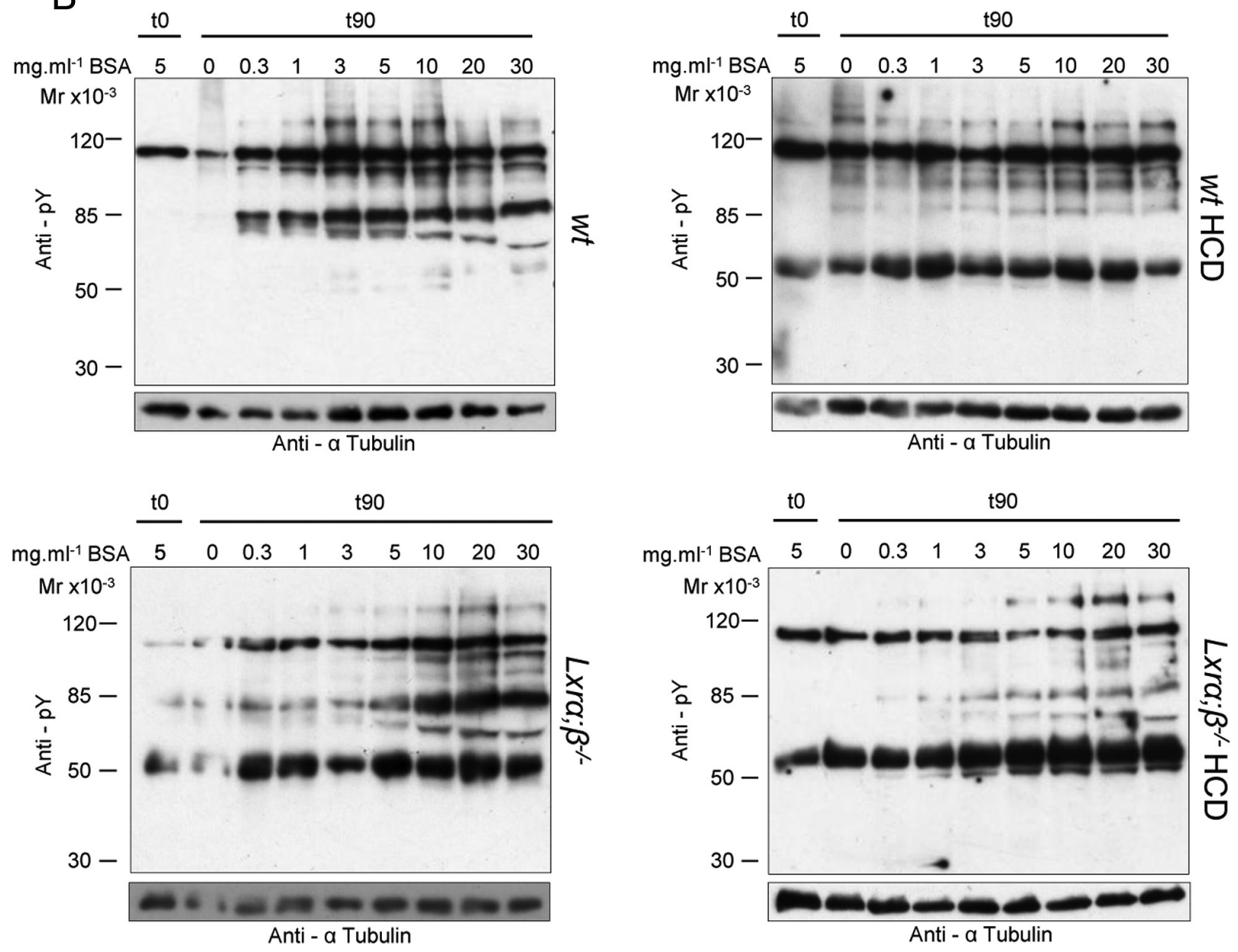

Figure 2 Capacitation efficiency determined with anti-phosphotyrosine Western blot. (A) Sperm from $w t$ and $L x r \alpha ; \beta^{-/-}$mice fed with control diet or HCD were incubated 0, 45 or 90 min in classical capacitation medium 1 or in medium 2 supplemented with 8-Bromo-CAMP and IBMX. Protein extracts were analyzed with anti-phosphotyrosine antibody. This experiment was performed four times with similar results. Alpha-tubulin was used as a control of the protein amount. (B) Sperm from $w t$ and $L x r \alpha ; \beta^{-/-}$mice fed with control diet or HCD were incubated 90 min in capacitation medium 1 containing increasing concentrations of BSA $(0,0.3,1,3,5,10,20,30 \mathrm{mg} / \mathrm{mL})$. Protein extracts were analyzed with anti-phosphotyrosine antibody. Each Western blot for each group is representative of four experiments. Alpha-tubulin was presented under each blot as a control of protein amount. 


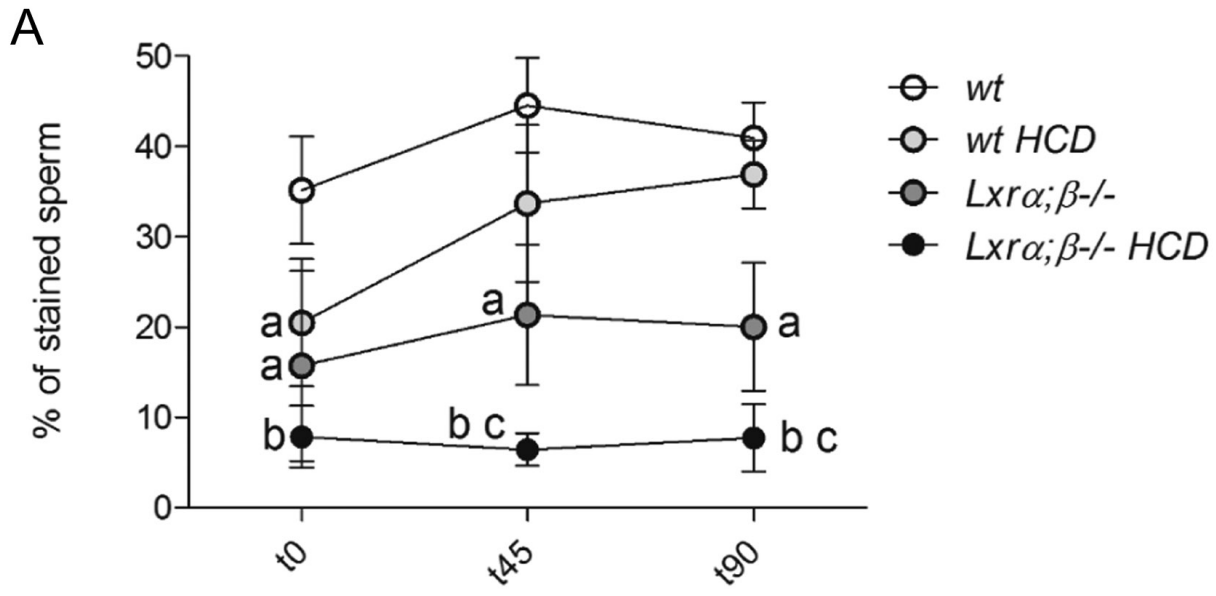

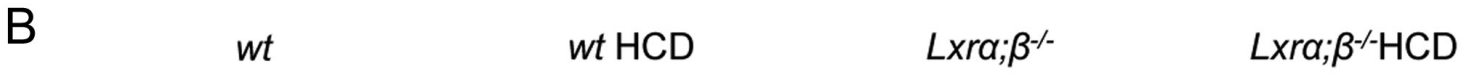

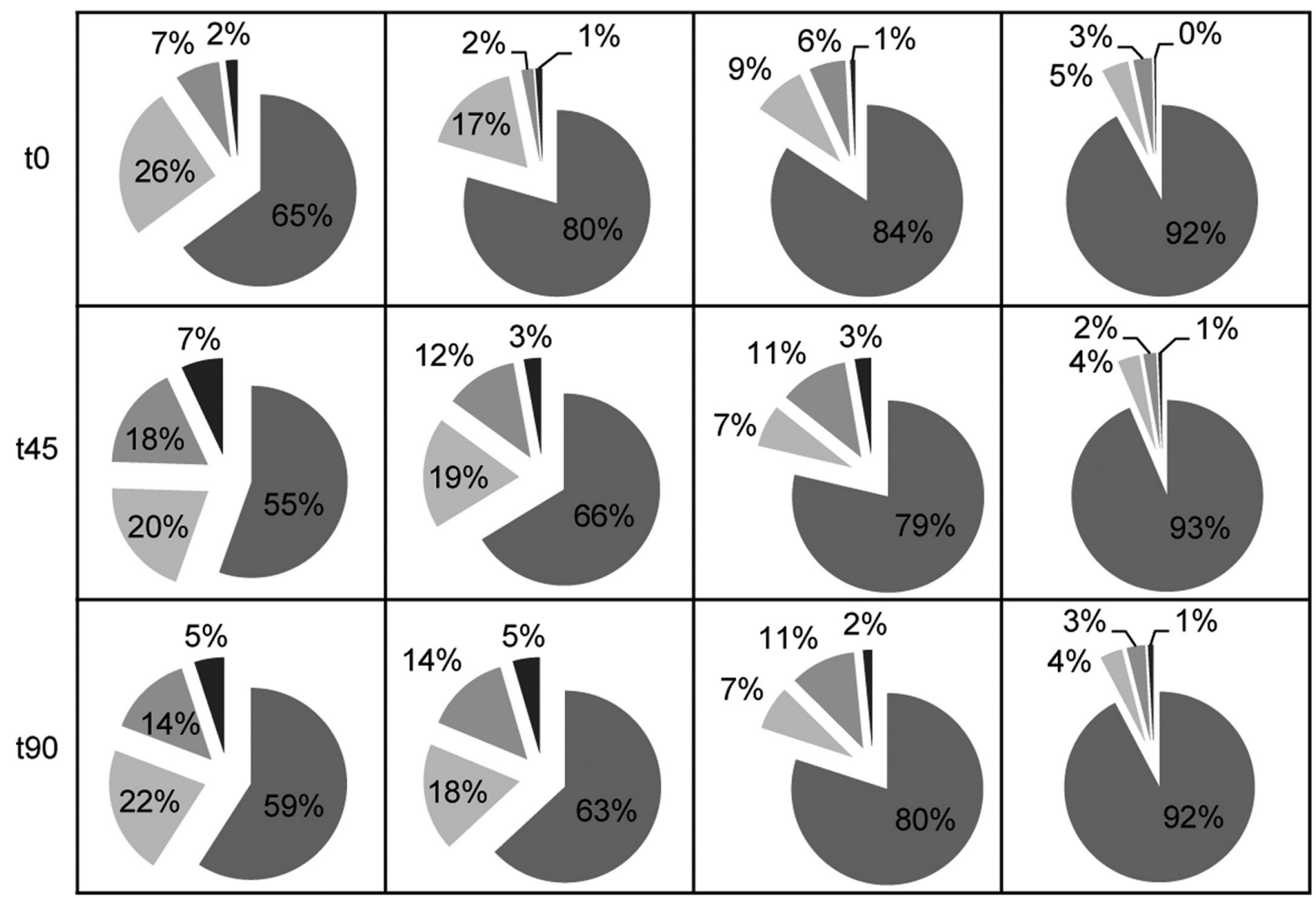

\section{Not stained}

\section{Tail stained}

Head stained

Head and tail stained

Figure 3 Evaluation of the percentage of tyrosine-phosphorylated sperm during capacitation. Sperm from control diet and HCD-fed wt and $L x r \alpha ; \beta^{-/-}$mice were incubated during 0,45 or $90 \mathrm{~min}$ in capacitation medium 1 prior tyrosine phosphorylation immunostaining. (A) After counting, the percentage of tyrosine-phosphorylated sperm was evaluated. The points are means \pm S.E.M. (B) Representation of subcellular staining distribution (not stained, tail stained, head stained or both) in percentage for each group at each time of capacitation. At least 200 sperm were counted per experiment, $n=4$, ${ }^{a} P<0.05$ vs $w t,{ }^{b} P<0.05$ vs $w t-H C D,{ }^{c} P<0.05$ vs $L x r \alpha ; \beta^{-/-}$(Mann-Whitney test). 
A
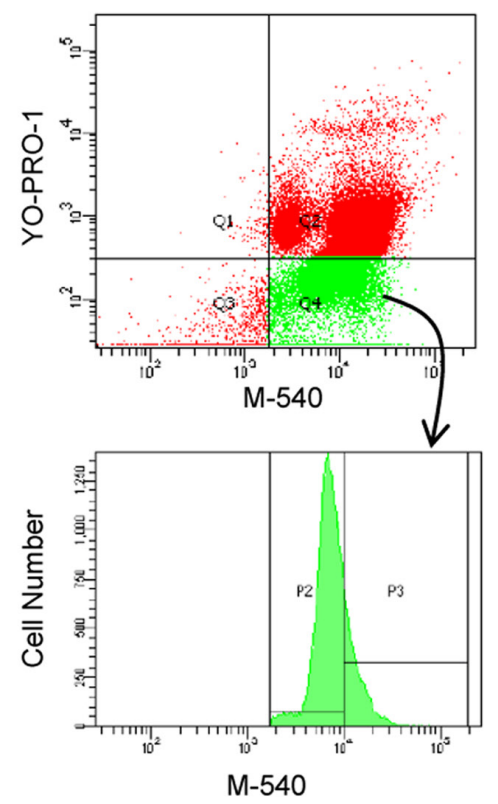

B

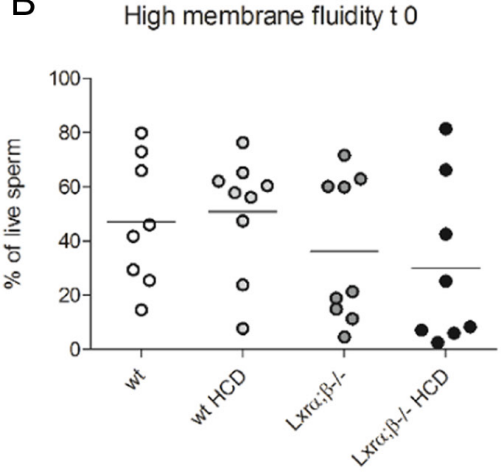

t 45
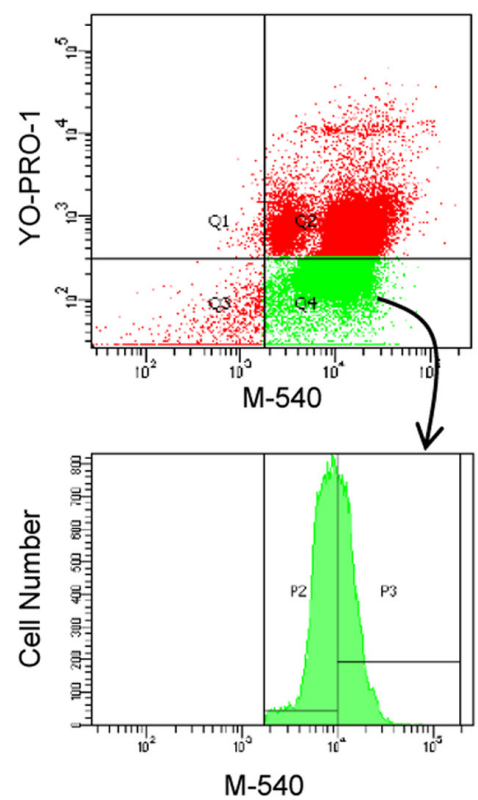

High membrane fluidity t 45

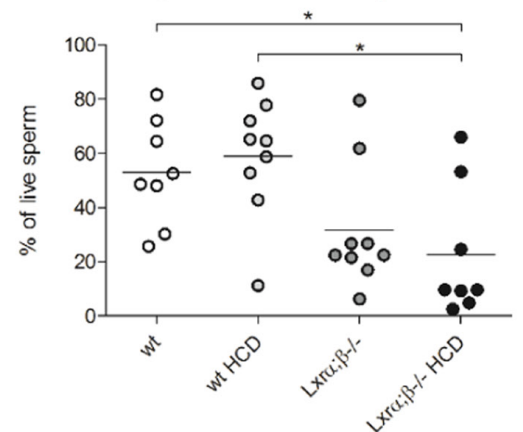

t 90

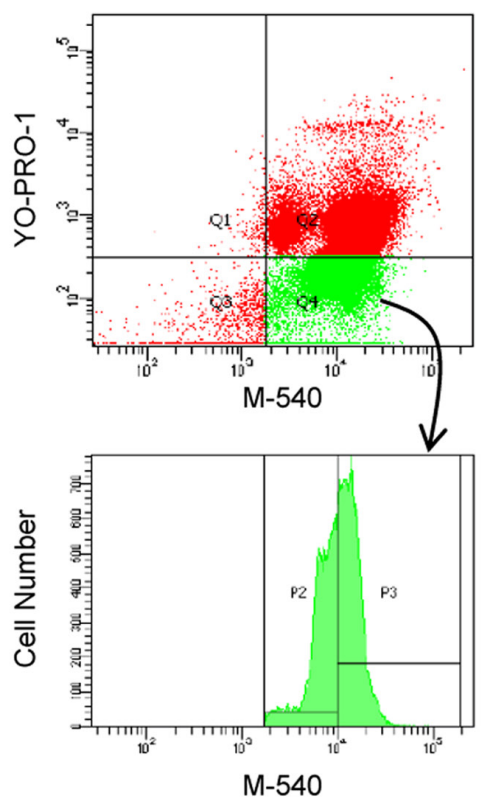

High membrane fluidity $\mathrm{t} 90$

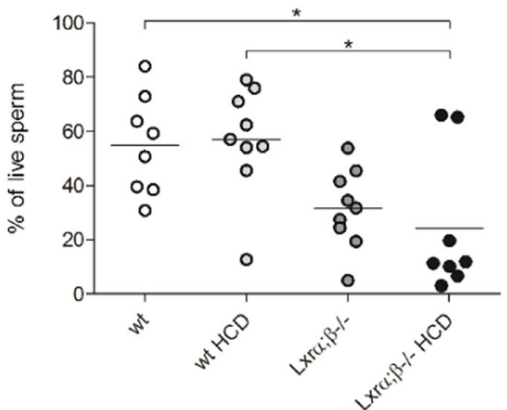

C

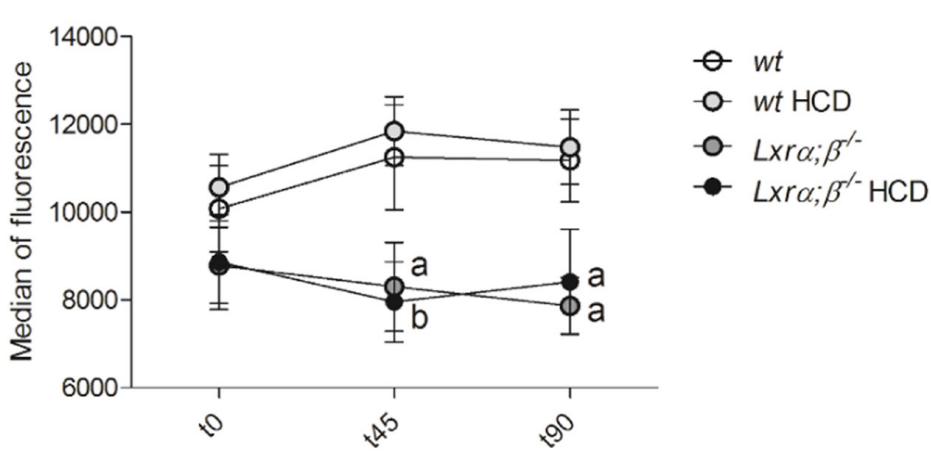

Figure 4 Evaluation of membrane fluidity using flow cytometry. Sperm from $w t$ and $L x r \alpha ; \beta^{-/}$mice fed with control diet or HCD were incubated 0,45 or 90 min in capacitation medium 1. YO-PRO-1 and merocyanine-540 were added to determine sperm viability and membrane fluidity, respectively, and $0.5 \times 10^{6}$ cells were acquired on an LSR II flow cytometer. (A) The upper panel shows cytograms with a green population representing live sperm stained with merocyanine-540 probe. The underlying histograms show the cell number of this green subpopulation depending on the intensity of merocyanine-540 fluorescence. Two subpopulations are visible: P2 with low membrane fluidity and P3 with high membrane fluidity. (B) Scatter dot plots represent the percentage of live sperm in P3 subpopulation (high membrane fluidity) during capacitation. Horizontal bars represent means. (C) Evolution of median fluorescence in merocyanine-540 in the green subpopulation during capacitation. The points are means \pm S.E.M. ${ }^{*} P<0.05$ between compared groups, ${ }^{\mathrm{a}} \mathrm{P}<0.05 \mathrm{vs} w t,{ }^{\mathrm{b}} \mathrm{P}<0.01 \mathrm{vs} w t-\mathrm{HCD}$ (Mann-Whitney test). $n=8 w t, 9 w t-\mathrm{HCD}, 9$ $L x r \alpha ; \beta^{-/}, 8$ Lxr $\alpha ; \beta^{-/-}$HCD. M-540, merocyanine-540. 
panels). There was also a similar tendency for $L x r \alpha ; \beta^{-/-}$ males fed with the control diet (compared to $w t$ ) at these two times of capacitation.

The median of fluorescence intensity measured on the Q4 subpopulation is related to the overall sperm membrane fluidity as it is dependent on the total amount of M-540 inserted in their membrane. When plotting this median of fluorescence to compare the groups, no significant difference was seen at t0. During the course of capacitation, it was clear that $L x r \alpha ; \beta^{-/-}$males fed with the control diet or the HCD had a significantly lower overall fluidity than the wt spermatozoa (Fig. 4C).

Overall, these results showed that fewer spermatozoa from $L x r \alpha ; \beta^{-/-}$males fed with the HCD had the ability to engage into capacitation as measured by the increase in membrane fluidity, and that their overall fluidity was lower than for the wt spermatozoa.

\section{Dyslipidemia alters sperm calcium fluxes during capacitation}

Calcium influx during capacitation is highly regulated and involved in the control of the signaling pathway triggered by membrane events. Alterations of the membrane dynamics may thus have impacts on these calcium fluxes. We used flow cytometry with Fluo4-AM to measure $\left[\mathrm{Ca}^{2+}\right]_{i}$ in capacitating spermatozoa from our four groups (Fig. 5). As seen for membrane fluidity in Fig. 4, living sperm in the Q4 quartile (Fig. 5A in green) were separated into two subpopulations of low (P2) and high (P3) $\left[\mathrm{Ca}^{2+}\right]_{\mathrm{i}}$. During the course of capacitation, the percentage of sperm cells in the P3 subpopulation normally increases as seen in the lower panel of Fig. 5A. At t0, the differences between groups were minimal and $\left[\mathrm{Ca}^{2+}\right]_{i}$ was low. There was a significant difference between wt-HCD and $L x r \alpha ; \beta^{-/-}$-HCD (Fig. 5B left panel, $P<0.05)$. During capacitation, the rise in $\left[\mathrm{Ca}^{2+}\right]_{i}$ was clearly visible between t0 and $t 45$ for all the groups (Fig. 5B, middle panel). Fewer spermatozoa from the $L x r \alpha ; \beta^{-/-}$males showed a high $\left[\mathrm{Ca}^{2+}\right]_{\mathrm{i}}$, with an effect of the diet at 990 as the difference was significant between $L x r \alpha ; \beta^{-/-}$and $L x r \alpha ; \beta^{-1-}$ HCD males (Fig. 5B, right panel, $P<0.05)$.

Here also, the median of fluorescence in the Q4 subpopulation was used to evaluate the relative $\left[\mathrm{Ca}^{2+}\right]_{\mathrm{i}}$ between groups. At t0, even though no significant difference appeared between groups, sperm from the $L x r \alpha ; \beta^{-1-}-\mathrm{HCD}$ males had a higher $\left[\mathrm{Ca}^{2+}\right]_{i}$ than those from $w t$ males, and this tendency was inverted at 190 (Fig. 5C, left panel). The ratio of the median fluorescence between 190 and t0 was calculated, and indicated the capacity of the sperm cells to elevate their $\left[\mathrm{Ca}^{2+}\right]_{i}$ during the course of capacitation. The difference was significant between $L x r \alpha ; \beta^{-/-}-H C D$ and each of the other groups (Fig. 5C, right panel).

Overall, these results showed that fewer spermatozoa from $L x r \alpha ; \beta^{-/-}$males fed with the HCD had the ability to engage in capacitation, as measured by the increase in $\left[\mathrm{Ca}^{2+}\right]_{i}$, and that their overall $\left[\mathrm{Ca}^{2+}\right]_{i}$ was lower than for the other groups at the end of capacitation. These results are in accordance with those from membrane fluidity measurements (Fig. 4). Indeed, there is a strong correlation between the subpopulations of high membrane fluidity and high intracellular calcium concentration at t90 (Fig. 6A, $r=0.5972, P<0.0002$ ). Increasing the BSA concentration in the capacitation medium from 5 to $20 \mathrm{mg} / \mathrm{mL}$ provoked a slight nonsignificant increase in the percentage of spermatozoa showing a high $\left[\mathrm{Ca}^{2+}\right]_{i}$, after capacitation, specifically in $L x r \alpha ; \beta^{-1-}$ males (Fig. 6B). This may explain the impact of BSA concentration on tyrosine phosphorylation shown in Fig. 2.

\section{Sperm calcium dysregulation comes from dyslipidemia- induced epididymal sperm maturation defect}

Calcium fluxes during capacitation are regulated by the activity of several proteins, including the major calcium efflux pump PMCA4 (plasma membrane calcium ATPase 4) and VDAC2 (voltage-dependent anion channel 2). VDAC2 was previously demonstrated as tyrosinephosphorylated during capacitation (Arcelay et al. 2008), while PMCA4 is known to be acquired during epididymal transit (Patel et al. 2013). These characteristics prompted us to evaluate their behavior in the $L x r \alpha ; \beta^{-/-}$-observed dysregulations of $\left[\mathrm{Ca}^{2+}\right]_{\mathrm{i}}$. We therefore first investigated the distribution of these proteins on cauda epididymal sperm from our four groups by Western blot. PMCA4 was shown to be significantly decreased in sperm from $L x r \alpha ; \beta^{-/-}$males fed with the HCD (compared to each of the other groups), whereas VDAC2 was stable among the groups (Fig. 7A). As PMCA4 has been shown to be acquired via epididymosomes during epididymal maturation, these vesicles were isolated from the cauda epididymis of $w t$ and $L x r \alpha ; \beta^{-1-}-\mathrm{HCD}$ males. The quantities of PMCA4 and VDAC2 were then measured by Western blot (Fig. 7B). Both PMCA4 and VDAC2 were less abundant on epididymosomes purified from $L x r \alpha ; \beta^{-/-}$HCD males compared to $w t$ males, even though these differences were not statistically significant due to variations between the different pools used for this study ( $P=0.3$ for PMCA4 and 0.0571 for VDAC2).

Tyrosine phosphorylation of VDAC2 and PMCA4 (although it is not yet known whether PMCA4 is Tyr-phosphorylated during capacitation) was evaluated, and tyrosine-phosphorylated proteins were immunoprecipitated from sperm of $w t$ and $L x r \alpha ; \beta^{-/-}$HCD males, at t0 and t90 of the capacitation process. VDAC2 and PMCA4 were measured by Western blot on the pool of immunoprecipitated proteins in order to evaluate the course of their tyrosine phosphorylation during capacitation. As previously described, VDAC2 was tyrosine-phosphorylated during capacitation under our two conditions (Fig. 8A). However, the level of 
A

t 0

a
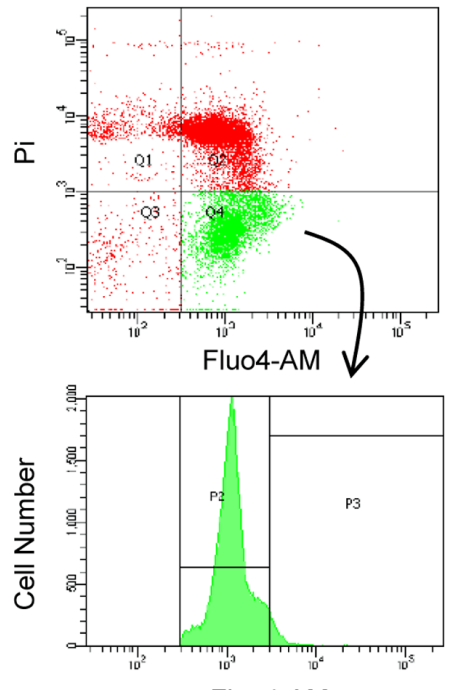

Fluo4-AM

B

High $\left[\mathrm{Ca}^{2+}\right]_{\mathrm{i}} \mathrm{t} \mathrm{O}$

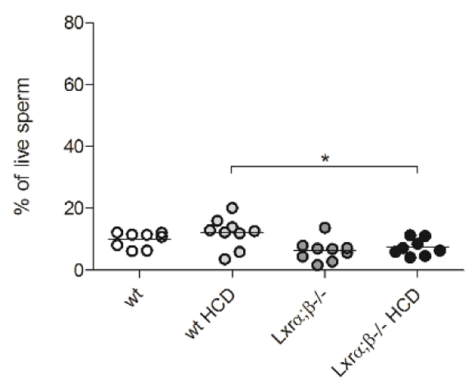

t 45
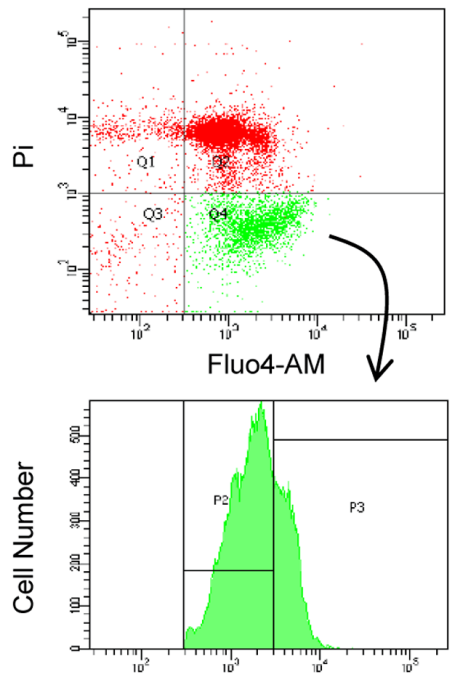

Fluo4-AM
High $\left[\mathrm{Ca}^{2+}\right]_{\mathrm{i}} \mathrm{t} 45$

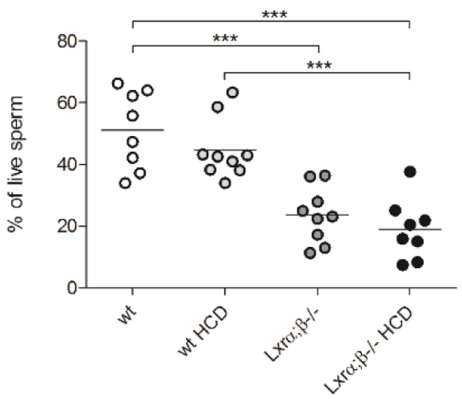

t 90
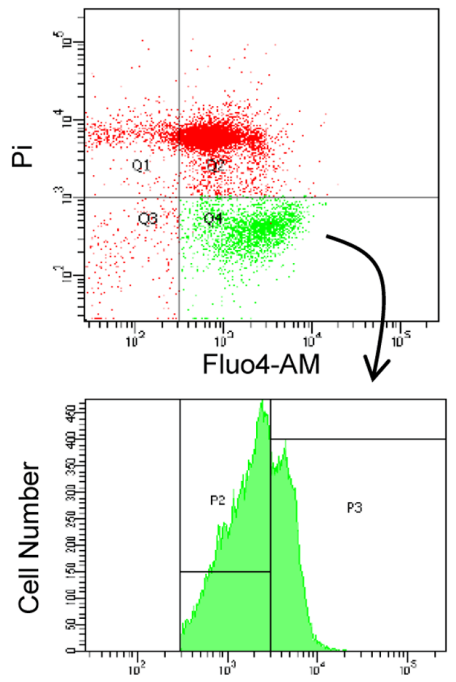

Fluo4-AM

C
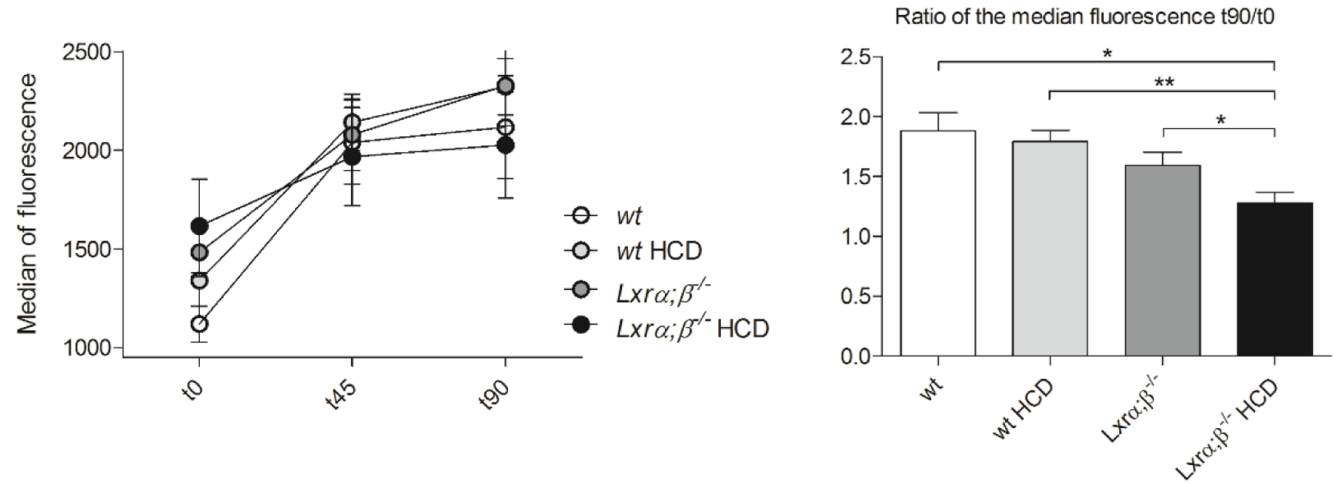

Figure 5 Determination of calcium fluxes during capacitation. Sperm from $w t$ and $L x r \alpha ; \beta^{-/-}$mice fed with control diet or HCD were incubated one hour with Fluo4-AM (to load sperm). Fluo4-AM emits fluorescence depending on intracellular calcium concentration as the probe is blocked in cells after hydrolysis of the ester group by cell esterase. Then, sperm were incubated 0,45 or 90 min in capacitation medium 1, Pi was added to determine sperm viability and $0.5 \times 10^{6}$ cells were acquired on an LSR II BD flow cytometer. (A) The upper panel shows cytograms with a green subpopulation representing live sperm that integrated Fluo4-AM probe. The underlying histograms show the cell number of this green subpopulation depending on the intensity of Fluo4-AM fluorescence. Two subpopulations are visible: P2 with low intracellular calcium concentration $\left(\left[\mathrm{Ca}^{2+}\right]_{\mathrm{i}}\right)$ and P3 with high $\left[\mathrm{Ca}^{2+}\right]_{i}$. (B) Scatter dot plots represent the percentage of live sperm in P3 subpopulation (high intracellular calcium concentration) during capacitation. Horizontal bars represent mean. (C) Evolution of the median fluorescence of Fluo4-AM in green subpopulation during capacitation (left panel), and median fluorescence ratio of t90 to t0 indicating the increase in $\left[\mathrm{Ca}^{2+}\right]_{i}$ during capacitation (right panel). The values are means \pm S.E.M. ${ }^{*} P<0.05,{ }^{* *} P<0.01,{ }^{* * *} P<0.001$ between compared groups (Mann-Whitney test). $n=8$ $w t, 9 w t-H C D, 9 L x r \alpha ; \beta^{-/-}, 8 L x r \alpha ; \beta^{-/-} \mathrm{HCD}$. Pi, propidium iodide. 
A High M540/High $\left[\mathrm{Ca}^{2+}\right]_{\mathrm{i}}$ Correlation

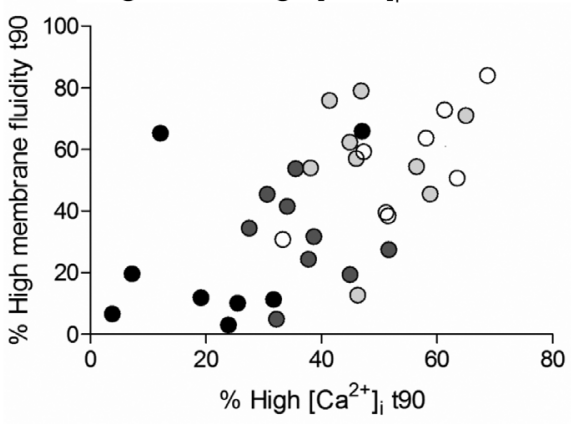

$\circ w t$

- wt $\mathrm{HCD}$

- $\operatorname{Lx} \alpha ; \beta^{1-}$

- $L x r \alpha ; \beta^{\prime-} H C D$

$r=0,5972$ $p<0,0002$

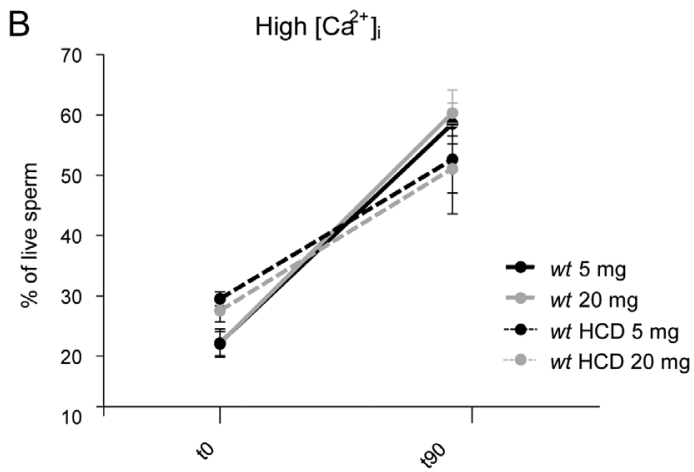

High $\left[\mathrm{Ca}^{2+}\right]$

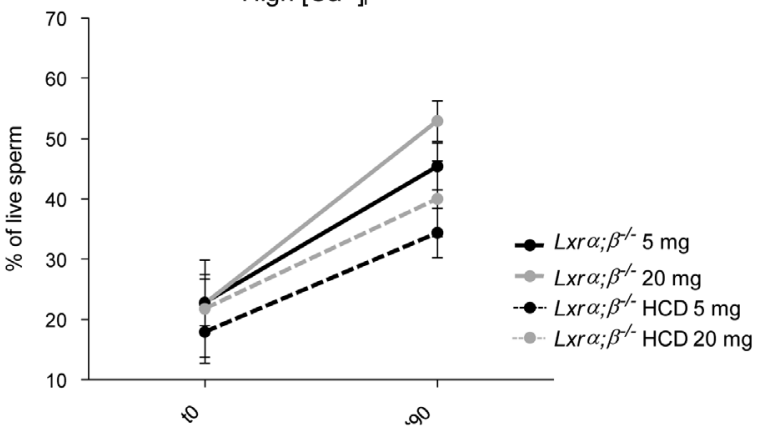

Figure 6 Correlation between high membrane fluidity and high intracellular calcium concentration sperm subpopulations at the end of capacitation (t90) and impact of BSA concentration on calcium fluxes. (A) Percentages of spermatozoa with high membrane fluidity were plotted against percentages of spermatozoa with high $\left[\mathrm{Ca}^{2+}\right]_{i}$ at $t=90 \mathrm{~min}$ of capacitation. Spearman correlation was used to examine the association between these two subpopulations. $r=0.5972$,

$P<0.0002(* * *)$, significance was determined at a confidence level of $95 \%$. (B) The calcium fluxes were determined by flow cytometry as described in Fig. 4. The graphs represent the percentage of live sperm with high intracellular calcium concentration during capacitation in a medium containing 5 or $20 \mathrm{mg} / \mathrm{mL}$ of BSA. The values are means \pm S.E.M. ( $n=4$ for each point).

VDAC2 tyrosine phosphorylation was higher at t0 in spermatozoa from $L x r \alpha ; \beta^{-/-}$-HCD males compared to $w t$ (Fig. 8A). When considering the fold of VDAC2 tyrosine phosphorylation during the course of capacitation, it was close to 2 for wt sperm, whereas it was slightly above 1 for $L x r \alpha ; \beta^{-1-}$-HCD males (Fig. 8B). PMCA4 also showed tyrosine phosphorylation at $\mathrm{t} 0$, but capacitation had no
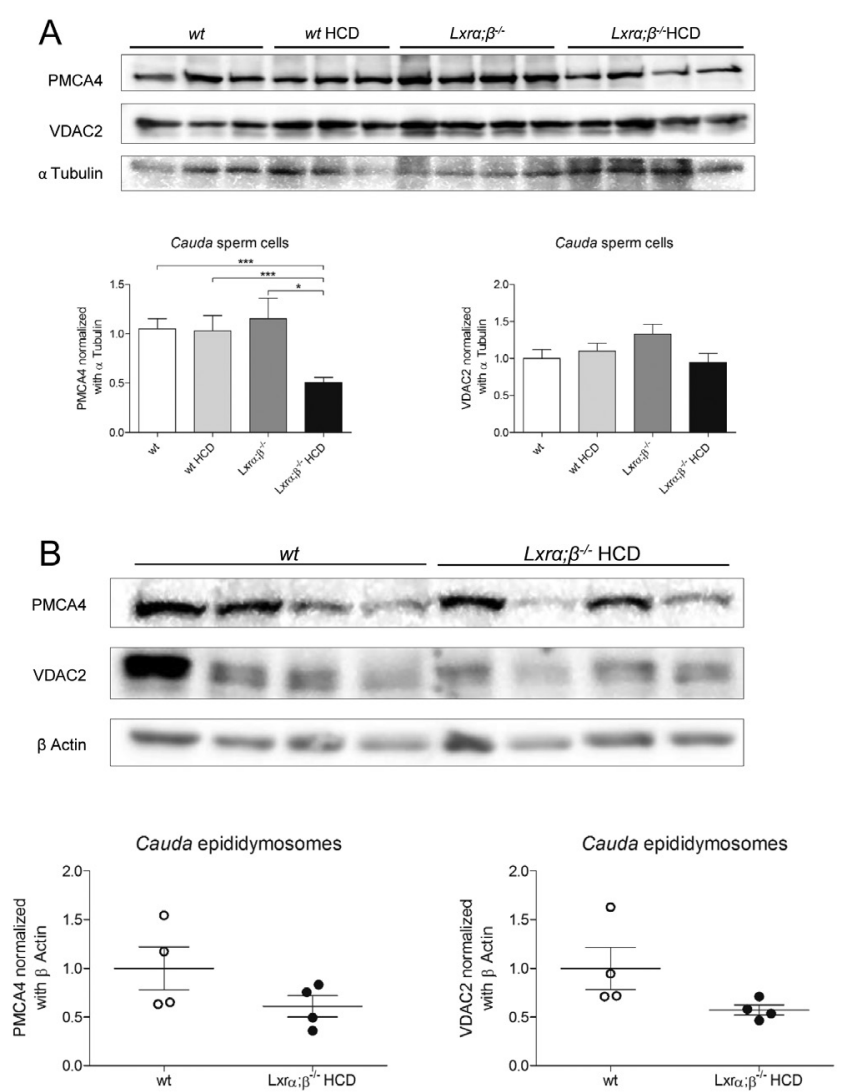

Figure 7 PMCA4 and VDAC2 protein levels in cauda sperm and epididymosomes. (A) Relative PMCA4 and VDAC2 protein levels in cauda sperm from $w t$ and $L x r \alpha ; \beta^{-/-}$mice fed with control or HCD diet. Alpha-tubulin was used as a control of protein amount for quantification. Bar graphs display means \pm S.E.M., $n=10 w t, 13$ $w t-H C D, 11$ Lxr $; \beta^{-/-}, 16$ Lxr $; \beta^{-/-}$HCD. (B) Relative PMCA4 and VDAC2 protein levels in cauda epididymosomes from $w t$ and $L x r \alpha ; \beta^{-/-}$HCD (each point represents epididymosomes from six mice). Beta-actin was used as a control of protein amount for quantification. In scatter dot plots, horizontal bars represent means \pm S.E.M., $n=4$. ${ }^{*} P<0.05,{ }^{* * *} P<0.001$ between compared groups (Mann-Whitney test).

effect on its level (Fig. 8C and D). For these two proteins, a certain heterogeneity appeared between individuals.

Overall, these data showed that spermatozoa from $L x r \alpha ; \beta^{-1-}$ HCD males had lower levels of PMCA4 than wt spermatozoa, and that the tyrosine phosphorylation of VDAC2 was altered at t0. The importance of these alterations in the dysregulations of $\left[\mathrm{Ca}^{2+}\right]_{i}$ will be discussed.

\section{Discussion}

Fat-rich regimens are mainly responsible for several serious and widespread illnesses such as obesity, diabetes and cardiovascular diseases. Such regimens are also known to impact reproductive capacities both in males and females (Seli et al. 2014, Katib 2015). In males, the focus has mainly been put on lipid-driven endocrine 
A

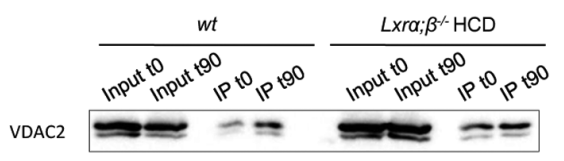

C

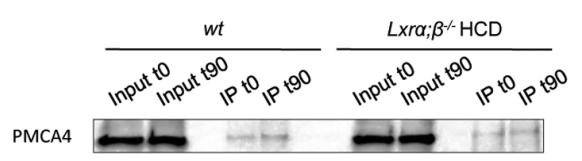

VDAC2

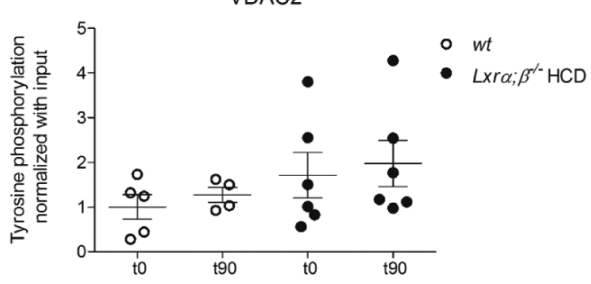

PMCA4

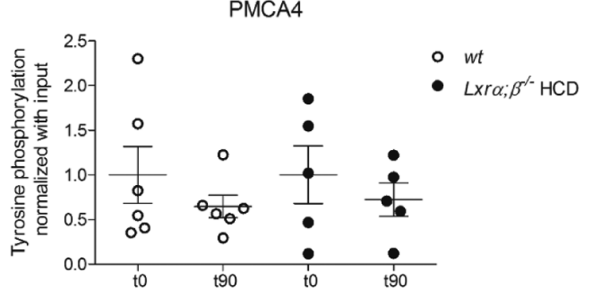

B

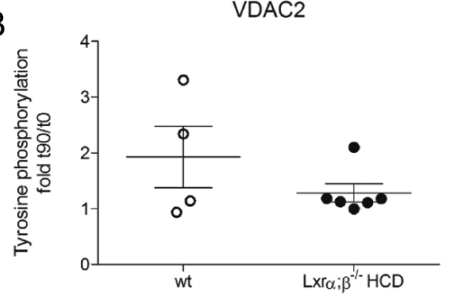

D

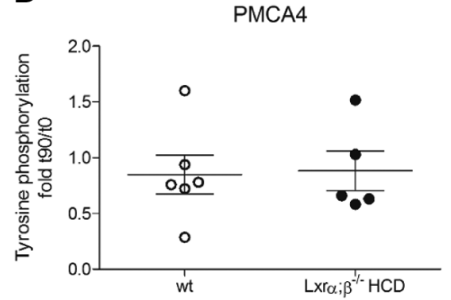

Figure 8 Analysis of PMCA4 and VDAC2 tyrosine phosphorylation during capacitation. Sperm from $w t$ and $L x r \alpha ; \beta^{-/-} H C D$ mice were incubated for 0 or $90 \mathrm{~min}$ in capacitation medium 1. Each time, total sperm proteins were extracted (40 million) and subjected to tyrosine-phosphorylated immunoprecipitation (IP). Input (representing a total protein amount before immunoprecipitation) and IP samples were subjected to SDS-PAGE and Western blotting was performed against VDAC2 (A) and PMCA4 (C). Scatter dot plots represent IP normalization with input. The increase in tyrosine phosphorylation for VDAC2 (B) and PMCA4 (D) during capacitation was calculated. In scatter dot plots, horizontal bars represent means \pm S.E.M. (PMCA4 $n=6 w t, 5 L x r \alpha ; \beta^{-/-}$HCD and VDAC2 $n=4 w t, 6 L x r \alpha ; \beta^{-/-}$HCD).

dysregulations of spermatogenesis. However, recent data pinpointed the epididymis and the post-testicular sperm maturation as an additional target of metabolic disorders, with the capacity to modify maturing sperm, ultimately leading to the eventual transmission of the disorders to the offspring (Chen et al. 2016, Sharma et al. 2016). Our data are totally in accordance with the observation that structure and functions of accessory organs of the male genital tract are impaired by diet-induced lipid disorders. We show that in our model of $L x r \alpha ; \beta^{-1-}-H C D-$ fed mice, dyslipidemia alters the epididymal function, sperm lipid composition and dynamics, as well as protein acquisition via epididymosomes, with negative consequences on sperm capacitation.

\section{Dyslipidemia alters sperm lipid composition}

In this model of $L x r \alpha ; \beta^{-/-}-H C D$-fed mice, the high level of susceptibility of epididymis to dietary cholesterol overload is highlighted. We had previously shown that cholesterol overload resulted in serious epididymal phenotype, characterized by intra-epithelial lipid accumulation, epithelium degeneration and the creation of an inflammatory environment, leading to name this phenotype 'epididymosclerosis' (Ouvrier et al. 2011). Here, we observed that epididymal maturation was disrupted with an impact on both sperm lipids and proteins. Lipid changes in $L x r \alpha ; \beta^{-/-}-\mathrm{HCD}$ sperm were subtle but sufficient to increase the Chol/PL and PE/PC ratios, translating into membrane stiffening. We could also observe an overall decrease in the oxysterol content in these spermatozoa. This is in favor of membrane stiffening, as oxidized sterols are known to promote membrane fluidity by causing lateral membrane expansion (Olkkonen \& Hynynen 2009). Oxysterols have recently been described in bovine (Brouwers et al. 2011), porcine and mouse sperm (Boerke et al. 2013). They were shown to play a role in the capacitation process and to move more freely out of the sperm membrane. They bind to acceptor proteins such as albumin due to their higher hydrophilic characteristics as compared to cholesterol (Aitken 2011). Taken together, these data indicate that the dyslipidemia-induced increase in the Chol/PL and PE/PC ratios associated with the reduction of oxysterols in $L x r \alpha ; \beta^{-/-}-H C D$ sperm may result in a decrease in membrane fluidity limiting the sterol efflux that triggers capacitation. Our hypothesis is supported by the observation that increasing the availability of the extracellular cholesterol acceptor by rising BSA concentration in the capacitation medium partially restored the efficiency of capacitation, as measured by tyrosine phosphorylation.

\section{Sperm lipid composition changes impair membrane dynamics and capacitation signaling cascade}

Flow cytometry data confirmed that membrane fluidity was impaired in sperm cells from $L x r \alpha ; \beta^{-/-}$-males fed the normal diet or the HCD. At t0, the median of fluorescence indicated a tendency to an increase in membrane rigidity in these spermatozoa, in accordance with the calculated chol/PL and PE/PC ratios. The difference was not significant probably because merocyanine-540 is not sensitive enough to slight fluidity variations, but 
this probe revealed significant differences during the course of capacitation. A significantly lower percentage of $L x r \alpha ; \beta^{-/-}$-HCD living sperm cells (dead sperm being excluded) were able to develop a high membrane fluidity during capacitation compared to $w t$. These data attest that spermatozoa in this lipid-mediated abnormal context (i.e. the $L x r \alpha ; \beta^{-/-}-\mathrm{HCD}$ ) have difficulty bringing their plasma membrane to an optimal state of fluidity.

Mammalian spermatozoa are very peculiar cells as their genetic material is silent, due to its very high degree of compaction, enabling its protection during the journey toward the fertilization site. Molecular events occurring during post-testicular maturation are consequently highly dependent on their membrane composition and dynamics. We demonstrated that the major problem for the $L x r \alpha ; \beta^{-/-}-H C D$ spermatozoa to achieve capacitation indeed resides at the plasma membrane level since the intracellular signaling events downstream of SAC and upstream of tyrosine kinases were perfectly normal. This was evidenced by the fact that a totally standard tyrosine phosphorylation profile could be obtained in vitro in all situations tested when using a classical (8-Bromo-cAMP + IBMX) capacitation medium known to provoke tyrosine phosphorylation in the absence of BSA (Visconti et al. 1995).

Calcium fluxes have been described as essential for the regulation of capacitation (Lishko et al. 2012). Calcium is involved in the signaling cascade regulating capacitation by participating in the SAC activation (Jaiswal \& Conti 2003), in the acquisition of the sperm hyperactivation movement (Navarrete et al. 2015) and in the triggering of the acrosome reaction (Navarrete et al. 2015). Sperm $\left[\mathrm{Ca}^{2+}\right]_{\mathrm{i}}$ is finely tuned by a set of ion channels (Lishko et al. 2012) because calcium can have a dual role as both an activator and an inhibitor of capacitation (Navarrete et al. 2015). During capacitation, fewer $L x r \alpha ; \beta^{-/-}-H C D$ sperm were able to acquire a high $\left[\mathrm{Ca}^{2+}\right]_{\mathrm{i}}$, showing dysregulations in capacitation-associated calcium influx. The observed dysregulations of $\left[\mathrm{Ca}^{2+}\right]_{i}$ were more subtle since basal $\left[\mathrm{Ca}^{2+}\right]_{i}$ was perturbed in $L x r \alpha ; \beta^{-/-}$with a tendency to be too elevated, and the calculated ratio of $\left[\mathrm{Ca}^{2+}\right]_{i}$ increase during capacitation was significantly impaired only in $L x r \alpha ; \beta^{-1-}-H C D$ sperm. The most studied calcium channels in relation to capacitation and hyperactivation are the CatSper (cation channels of sperm) channels, which are activated by the rise in intracellular $\mathrm{pH}$ during capacitation (Kirichok et al. 2006). These channels have been proven as essential for male fertility based on the fact that male mice lacking any of the CatSper1-4 or $\delta$ genes are infertile, due to a lack of hyperactivated motility and capacitation defects (Quill et al. 2003, Chung et al. 2011). However, CatSper1-null spermatozoa show a spontaneous and dramatic increase in tyrosine phosphorylation, which is further enhanced upon capacitation (Chung et al. 2014). This is not in accordance with our phenotype in which hypo-phosphorylation was described. In addition, to our knowledge, Catsper channels have never been described as tyrosine-phosphorylated during capacitation.

\section{Dyslipidemia is associated with a decrease in sperm- PMCA4 accumulation}

The regulation of sperm $\left[\mathrm{Ca}^{2+}\right]_{i}$ depends on several important ion channels and efflux pumps, a major one being the calcium pump PMCA4. PMCAs are a family of enzymes that extrude calcium from the cytosol across the plasma membrane of eukaryotic cells. The tissuespecific expression pattern of different isoforms and splice variants of the pump in mammalian tissues strongly suggest a specific physiological function (Strehler \& Zacharias 2001). PMCA4-deficient mice have revealed the importance of this isoform in male fertility as males are infertile due to impaired sperm motility, associated with $\left[\mathrm{Ca}^{2+}\right]_{\mathrm{i}}$ that is two times higher than in wild-type sperm (Okunade et al. 2004). The decrease in PMCA4 protein accumulation we observed in our model could explain the tendency for the calcium concentration to increase at t0 of capacitation. PMCA4 is partially acquired by spermatozoa during spermatogenesis in the testes, and is also transferred to sperm during epididymal transit via epididymosomes (Patel et al. 2013). In mouse sperm, PMCA4 was localized in lipid rafts over the acrosome and the proximal principal piece (Aravindan et al. 2012), and it can be delivered in these regions by extracellular vesicles (oviductosomes) by a fusogenic mechanism (Al-Dossary et al. 2015). Our data showed that the decrease in the amount of sperm PMCA4 in $L x r \alpha ; \beta^{-{ }^{-}}$$\mathrm{HCD}$ sperm was due to a lower epididymosome content and thus probably also due to a default in its acquisition by maturing sperm. The inter-individual heterogeneity observed in the amount of sperm PMCA4 (and VDAC2) may be related to different storage times of caudal spermatozoa, allowing the transfer of higher amounts of proteins for those residing for a longer period. This is supported by the fact that protein accumulation in testes or caput epididymis is not different among our four groups (Supplementary Fig. 1, see section on supplementary data given at the end of this article). The difference observed for the cauda epididymis is in accordance with this hypothesis. The cause of PMCA4 decrease in spermatozoa remains elusive as it could be related to either a decrease in epididymosomes production, to an alteration of the PMCA4 transfer to spermatozoa, or both. However, it seems that it is not due to a decrease in the expression of the Pmca4 gene as shown by qPCR data presented in Supplementary Fig. 2, where the expression level was similar between groups in all the tissues explored. A hypothesis could be that dyslipidemia-induced epididymal alterations may modify the lipid composition and thus the membrane structure of epididymosomes. Indeed, these vesicles are characterized by a high cholesterol/phospholipid 
ratio and a sphingomyelin enrichment (Rejraji et al. 2006). These two characteristics are signatures of lipid raft microdomains, and it was previously shown that PMCA pumps were concentrated in lipid rafts (Fujimoto 1993). As it has also been shown that, during bovine epididymal maturation, proteins could be specifically transferred from rafts and non-rafts domains of epididymosomes to the corresponding sperm domains (Girouard et al. 2009), it would be interesting to further investigate epididymosome composition and structure in our model.

A possible link between PMCA4 function and its tyrosine phosphorylation was shown in sensory neurons in which PMCA4 was under tonic inhibition by a member of the Src family of tyrosine kinase (SFKs, (Ghosh et al. 2011)). SFKs did not appear to directly phosphorylate PMCA4 but instead activated focal adhesion kinase which performs the PMCA4 tyrosine phosphorylation. These kinases are known to be involved during capacitation (Roa-Espitia et al. 2016), implying that PMCA4 could also be regulated by tyrosine phosphorylation in this process. We tested this hypothesis using an immunoprecipitation technique of the tyrosine-phosphorylated proteins during the course of capacitation and showed that PMCA4 was tyrosine-phosphorylated in a basal state, i.e., at t0 of capacitation, and that this phosphorylation did not evolve during capacitation. PMCA4 does not seem to be regulated by tyrosine phosphorylation during mouse sperm capacitation.

\section{Dyslipidemia alters capacitation-associated VDAC2 tyrosine phosphorylation}

VDAC2 is another interesting candidate to explain the sperm $\left[\mathrm{Ca}^{2+}\right]_{i}$ alterations. It is a voltage-dependent anion channel which forms pores originally identified in mitochondrial outer membranes of eukaryotic cells (Schein et al. 1976). VDACs have also been characterized in the plasma membrane of different cell types (reviewed by Shoshan-Barmatz et al. (2009)). VDAC2 was localized by immunofluorescence on the plasma membrane of the sperm head and flagellum in human (Liu et al. 2011), mouse (Arcelay et al. 2008) and bovine (Hinsch et al. 2001). One of its functions is to transport calcium either into the cytoplasm or into the mitochondrial intermembrane space (Gincel et al. 2001). Its precise role in male fertility is not elucidated yet, but different studies have shown its importance in $\left[\mathrm{Ca}^{2+}\right]_{i}$ regulation (Paradowska et al. 2006, Liu et al. 2011). VDAC2 was also shown as involved in the calcium influx regulation during mouse sperm capacitation (Kwon et al. 2013) as its pharmacological inhibition limited the efficiency of this process. Moreover, VDAC2 is known to be tyrosine-phosphorylated during capacitation in human
(Ficarro et al. 2003), buffalo (Jagan Mohanarao \& Atreja 2012) and mouse (Arcelay et al. 2008). In agreement with the literature, we showed that VDAC2 tyrosine phosphorylation had a tendency to increase during capacitation in wt sperm. This mechanism was altered in $L x r \alpha ; \beta^{-/-}-H C D$ sperm, with a higher basal level of VDAC2 tyrosine phosphorylation compared to $w t$ sperm at t0 (Fig. 6). The link between VDAC2 tyrosine phosphorylation and its activity as a calcium channel is still not clear. However, as shown in several species, one could assume that the increase in VDAC2 tyrosine phosphorylation during the capacitation process could favor the opening of this channel and the rise in $\left[\mathrm{Ca}^{2+}\right]_{i}$. We thus propose that the higher $\left[\mathrm{Ca}^{2+}\right]_{i}$ in $L x r \alpha ; \beta^{-/-}-\mathrm{HCD}$ sperm at t0 could be due to a higher VDAC2 activity (in relation to a higher tyrosine phosphorylation level) associated with a low quantity of PMCA4. During the course of capacitation, other channels, such as Catsper, are normally activated, and the capacitated cells reach a normally high $\left[\mathrm{Ca}^{2+}\right]_{i}$. In $L x r \alpha ; \beta^{-/-}-\mathrm{HCD}$ animals, fewer spermatozoa have the ability to undergo the normal capacitation process, as their epididymal maturation leads to an abnormal membrane composition and dynamics. This study also showed, for the first time, the presence of VDAC2 in mouse epididymosomes, which implies that it may also be transferred to spermatozoa during the epididymal transit, emphasizing its role in the capacitation process.

In conclusion, in our model, dyslipidemia-induced infertility could reside at least partially in the alteration of the acquisition of $\mathrm{Ca}^{2+}$-regulating proteins during sperm maturation via epididymosomes, consequently altering sperm capacitation. Lipids seem to play a central role in this process either by interfering with sperm membrane maturation, epididymosome production and composition, epididymosome-sperm interaction or all these parameters together. Further investigations will be needed to test these hypotheses. Epididymosomes appear as central elements for post-testicular maturation and are highly sensitive to metabolic disorders. Finally, characterization of sperm-related molecules associated with dyslipidemia-induced infertility, such as PMCA4 or VDAC2, may introduce new areas of research to better understand unexplained male infertility associated with undiagnosed dyslipidemia.

\section{Supplementary data}

This is linked to the online version of the paper at http://dx.doi.org/10.1530/REP-17-0467.

\section{Declaration of interest}

The authors declare that there is no conflict of interest that could prejudice the impartiality of the present research. 


\section{Funding}

Work supported by the French Ministry of Higher Education and Research (MESR), INSERM, CNRS, the French National Institute for Agricultural Research (INRA), Conseil Régional Bourgogne, Franche-Comté (PARI grant) and FEDER (European Funding for Regional Economic Development).

\section{Acknowledgements}

The authors would like to thank the lipidomic platform 'Metatoul' in Toulouse, Christelle Blavignac from the CICS (Centre Imagerie Cellulaire Santé - Clermont-Ferrand) for flow cytometry analyses, Sandrine Plantade, Kirrhedine Ouchen and Philippe Mazuel for animal facility management, the Chester team (GReD - Clermont-Ferrand) for the use of the knockout mice and Lucy Martine (UMR CSGA - Dijon) for her help in oxysterol analyses. The authors also thank Catherine Bryan for reviewing the language throughout the manuscript.

\section{References}

Aitken RJ 2011 The capacitation-apoptosis highway: oxysterols and mammalian sperm function. Biology of Reproduction 85 9-12. (doi:10.1095/biolreprod.111.092528)

Al-Dossary AA, Bathala P, Caplan JL \& Martin-DeLeon PA 2015 Oviductosome-sperm membrane interaction in cargo delivery: detection of fusion and underlying molecular players using threedimensional super-resolution structured illumination microscopy (SRSIM). Journal of Biological Chemistry 290 17710-17723. (doi:10.1074/ jbc.M114.633156)

Aravindan RG, Fomin VP, Naik UP, Modelski MJ, Naik MU, Galileo DS, Duncan RL \& Martin-Deleon PA 2012 CASK interacts with PMCA4b and JAM-A on the mouse sperm flagellum to regulate Ca2+ homeostasis and motility. Journal of Cellular Physiology 227 3138-3150. (doi:10.1002/ jcp.24000)

Arcelay E, Salicioni AM, Wertheimer E \& Visconti PE 2008 Identification of proteins undergoing tyrosine phosphorylation during mouse sperm capacitation. International Journal of Developmental Biology $\mathbf{5 2}$ 463-472. (doi:10.1387/ijdb.072555ea)

Austin CR 1952 The capacitation of the mammalian sperm. Nature $\mathbf{1 7 0}$ 326. (doi:10.1038/170326a0)

Bligh EG \& Dyer WJ 1959 A rapid method of total lipid extraction and purification. Canadian Journal of Biochemistry and Physiology 37 911-917. (doi:10.1139/o59-099)

Boerke A, Brouwers JF, Olkkonen VM, van de Lest $\mathrm{CH}$, Sostaric E, Schoevers EJ, Helms JB \& Gadella BM 2013 Involvement of bicarbonateinduced radical signaling in oxysterol formation and sterol depletion of capacitating mammalian sperm during in vitro fertilization. Biology of Reproduction 88 21. (doi:10.1095/biolreprod.112.101253)

Brouwers JF, Boerke A, Silva PF, Garcia-Gil N, van Gestel RA, Helms JB, van de Lest $\mathbf{C H}$ \& Gadella BM 2011 Mass spectrometric detection of cholesterol oxidation in bovine sperm. Biology of Reproduction 85 128-136. (doi:10.1095/biolreprod.111.091207)

Chang MC 1951 Fertilizing capacity of spermatozoa deposited into the fallopian tubes. Nature 168 697-698. (doi:10.1038/168697b0)

Chavez JC, Hernandez-Gonzalez EO, Wertheimer E, Visconti PE, Darszon A \& Trevino CL 2012 Participation of the $\mathrm{Cl}-/ \mathrm{HCO}(3)$ exchangers SLC26A3 and SLC26A6, the Cl-channel CFTR, and the regulatory factor SLC9A3R1 in mouse sperm capacitation. Biology of Reproduction 86 1-14. (doi:10.1095/biolreprod.111.094037)

Chen Q, Yan M, Cao Z, Li X, Zhang Y, Shi J, Feng GH, Peng H, Zhang X, Zhang $\mathbf{Y}$ et al. 2016 Sperm tsRNAs contribute to intergenerational inheritance of an acquired metabolic disorder. Science 351 397-400. (doi:10.1126/science.aad7977)

Chung JJ, Navarro B, Krapivinsky G, Krapivinsky L \& Clapham DE 2011 A novel gene required for male fertility and functional CATSPER channel formation in spermatozoa. Nature Communications 2 153. (doi:10.1038/ ncomms1153)

Chung JJ, Shim SH, Everley RA, Gygi SP, Zhuang X \& Clapham DE 2014 Structurally distinct $\mathrm{Ca}(2+)$ signaling domains of sperm flagella orchestrate tyrosine phosphorylation and motility. Cell 157 808-822. (doi:10.1016/j.cell.2014.02.056)

Cornwall GA 2009 New insights into epididymal biology and function. Human Reproduction Update 15 213-227. (doi:10.1093/humupd/ dmn055)

Dacheux JL, Gatti JL \& Dacheux F 2003 Contribution of epididymal secretory proteins for spermatozoa maturation. Microscopy Research and Technique 61 7-17. (doi:10.1002/jemt.10312)

Ferrieres J 2008 Prévalence des différentes dyslipidémies en France. Revues Generales: Risque Cardiovasculaire.

Ficarro S, Chertihin O, Westbrook VA, White F, Jayes F, Kalab P, Marto JA, Shabanowitz J, Herr JC, Hunt DF et al. 2003 Phosphoproteome analysis of capacitated human sperm. Evidence of tyrosine phosphorylation of a kinase-anchoring protein 3 and valosin-containing protein/p97 during capacitation. Journal of Biological Chemistry 278 11579-11589. (doi:10.1074/jbc.M202325200)

Folch J, Lees M \& Sloane Stanley GH 1957 A simple method for the isolation and purification of total lipides from animal tissues. Journal of Biological Chemistry 226 497-509.

Fourgeux C, Martine L, Pasquis B, Maire MA, Acar N, CreuzotGarcher C, Bron A \& Bretillon L 2012 Steady-state levels of retinal 24S-hydroxycholesterol are maintained by glial cells intervention after elevation of intraocular pressure in the rat. Acta Ophthalmologica 90 e560-e567. (doi:10.1111/j.1755-3768.2012.02490.x)

Frenoux JM, Vernet P, Volle DH, Britan A, Saez F, Kocer A, HenryBerger J, Mangelsdorf DJ, Lobaccaro JM \& Drevet JR 2004 Nuclear oxysterol receptors, LXRs, are involved in the maintenance of mouse caput epididymidis structure and functions. Journal of Molecular Endocrinology 33 361-375. (doi:10.1677/jme.1.01515)

Fujimoto T 1993 Calcium pump of the plasma membrane is localized in caveolae. Journal of Cell Biology 120 1147-1157. (doi:10.1083/ jcb.120.5.1147)

Ghosh B, Li Y \& Thayer SA 2011 Inhibition of the plasma membrane Ca2+ pump by CD44 receptor activation of tyrosine kinases increases the action potential afterhyperpolarization in sensory neurons. Journal of Neuroscience 31 2361-2370. (doi:10.1523/JNEUROSCI.5764-10.2011)

Gincel D, Zaid H \& Shoshan-Barmatz V 2001 Calcium binding and translocation by the voltage-dependent anion channel: a possible regulatory mechanism in mitochondrial function. Biochemical Journal 358 147-155. (doi:10.1042/bj3580147)

Girouard J, Frenette G \& Sullivan R 2009 Compartmentalization of proteins in epididymosomes coordinates the association of epididymal proteins with the different functional structures of bovine spermatozoa. Biology of Reproduction 80 965-972. (doi:10.1095/biolreprod.108.073551)

Grandgirard A, Martine L, Joffre C, Juaneda P \& Berdeaux O 2004 Gas chromatographic separation and mass spectrometric identification of mixtures of oxyphytosterol and oxycholesterol derivatives application to a phytosterol-enriched food. Journal of Chromatography $A \mathbf{1 0 4 0}$ 239-250. (doi:10.1016/j.chroma.2004.04.008)

Hinsch KD, Asmarinah, Hinsch, E \& Konrad L 2001 VDAC2 (porin-2) expression pattern and localization in the bovine testis. Biochimica et Biophysica Acta 1518 329-333. (doi:10.1016/S0167-4781(01)00199-3)

Jagan Mohanarao G \& Atreja SK 2012 Identification of NO induced and capacitation associated tyrosine phosphoproteins in buffalo (Bubalus bubalis) spermatozoa. Research in Veterinary Science 93 618-623. (doi:10.1016/j.rvsc.2011.09.017)

Jaiswal BS \& Conti M 2003 Calcium regulation of the soluble adenylyl cyclase expressed in mammalian spermatozoa. PNAS $\mathbf{1 0 0}$ 10676-10681. (doi:10.1073/pnas.1831008100)

Joffres M, Shields M, Tremblay MS \& Connor Gorber S 2013 Dyslipidemia prevalence, treatment, control, and awareness in the Canadian Health Measures Survey. Canadian Journal of Public Health 104 e252-e257. (doi:10.17269/cjph.104.3783)

Katib A 2015 Mechanisms linking obesity to male infertility. Central European Journal of Urology 68 79-85. (doi:10.1016/j.eururo.2015.05.013)

Kirichok Y, Navarro B \& Clapham DE 2006 Whole-cell patch-clamp measurements of spermatozoa reveal an alkaline-activated Ca2+ channel. Nature 439 737-740. (doi:10.1038/nature04417) 
Kwon WS, Park YJ, Mohamed el SA \& Pang MG 2013 Voltage-dependent anion channels are a key factor of male fertility. Fertility and Sterility $\mathbf{9 9}$ 354-361. (doi:10.1016/j.fertnstert.2012.09.021)

Lishko PV, Kirichok Y, Ren D, Navarro B, Chung JJ \& Clapham DE 2012 The control of male fertility by spermatozoan ion channels. Annual Review of Physiology 74 453-475. (doi:10.1146/annurev-physiol-020911-153258)

Liu B, Wang P, Wang Z \& Zhang W 2011 The use of anti-VDAC2 antibody for the combined assessment of human sperm acrosome integrity and ionophore A23187-induced acrosome reaction. PLOS ONE 6 e16985. (doi:10.1371/journal.pone.0016985)

Maqdasy S, Trousson A, Tauveron I, Volle DH, Baron S \& Lobaccaro JM 2016 Once and for all, LXRalpha and LXRbeta are gatekeepers of the endocrine system. Molecular Aspects of Medicine 49 31-46. (doi:10.1016/j.mam.2016.04.001)

Mozaffarian D, Benjamin EJ, Go AS, Arnett DK, Blaha MJ, Cushman M, de Ferranti S, Despres JP, Fullerton HJ, Howard VJ et al. 2015 Heart disease and stroke statistics - 2015 update: a report from the American Heart Association. Circulation 131 e29-e322. (doi:10.1161/ CIR.0000000000000152)

Nassar A, Mahony M, Morshedi M, Lin MH, Srisombut C \& Oehninger S 1999 Modulation of sperm tail protein tyrosine phosphorylation by pentoxifylline and its correlation with hyperactivated motility. Fertility and Sterility 71 919-923. (doi:10.1016/S0015-0282(99)00013-8)

Navarrete FA, Garcia-Vazquez FA, Alvau A, Escoffier J, Krapf D, SanchezCardenas C, Salicioni AM, Darszon A \& Visconti PE 2015 Biphasic role of calcium in mouse sperm capacitation signaling pathways. Journal of Cellular Physiology 230 1758-1769. (doi:10.1002/jcp.24873)

Okunade GW, Miller ML, Pyne GJ, Sutliff RL, O'Connor KT, Neumann JC, Andringa A, Miller DA, Prasad V, Doetschman T et al. 2004 Targeted ablation of plasma membrane Ca2+-ATPase (PMCA) 1 and 4 indicates a major housekeeping function for PMCA1 and a critical role in hyperactivated sperm motility and male fertility for PMCA4. Journal of Biological Chemistry 279 33742-33750. (doi:10.1074/jbc. M404628200)

Olkkonen VM \& Hynynen R 2009 Interactions of oxysterols with membranes and proteins. Molecular Aspects of Medicine 30 123-133. (doi:10.1016/j.mam.2009.02.004)

Ouvrier A, Cadet R, Vernet P, Laillet B, Chardigny JM, Lobaccaro JM, Drevet JR \& Saez F 2009 LXR and ABCA1 control cholesterol homeostasis in the proximal mouse epididymis in a cell-specific manner. Journal of Lipid Research 50 1766-1775. (doi:10.1194/jlr.M800657-JLR200)

Ouvrier A, Alves G, Damon-Soubeyrand C, Marceau G, Cadet R, Janny L, Brugnon F, Kocer A, Pommier A, Lobaccaro JM et al. 2011 Dietary cholesterol-induced post-testicular infertility. PLOS ONE 6 e26966. (doi:10.1371/journal.pone.0026966)

Paradowska A, Bohring C, Krause E \& Krause W 2006 Identification of evolutionary conserved mouse sperm surface antigens by human antisperm antibodies (ASA) from infertile patients. American Journal of Reproductive Immunology 55 321-330. (doi:10.1111/j.16000897.2006.00367.x)

Patel R, Al-Dossary AA, Stabley DL, Barone C, Galileo DS, Strehler EE \& Martin-DeLeon PA 2013 Plasma membrane Ca2+-ATPase 4 in murine epididymis: secretion of splice variants in the luminal fluid and a role in sperm maturation. Biology of Reproduction 89 6. (doi:10.1095/ biolreprod.113.108712)

Quill TA, Sugden SA, Rossi KL, Doolittle LK, Hammer RE \& Garbers DL 2003 Hyperactivated sperm motility driven by CatSper2 is required for fertilization. PNAS 100 14869-14874. (doi:10.1073/pnas.2136654100)

Rejraji H, Sion B, Prensier G, Carreras M, Motta C, Frenoux JM, Vericel E, Grizard G, Vernet P \& Drevet JR 2006 Lipid remodeling of murine epididymosomes and spermatozoa during epididymal maturation. Biology of Reproduction 74 1104-1113. (doi:10.1095/ biolreprod.105.049304)

Roa-Espitia AL, Hernandez-Rendon ER, Baltierrez-Hoyos R, MunozGotera RJ, Cote-Velez A, Jimenez I, Gonzalez-Marquez H \& Hernandez-Gonzalez EO 2016 Focal adhesion kinase is required for actin polymerization and remodeling of the cytoskeleton during sperm capacitation. Biology Open 5 1189-1199. (doi:10.1242/bio.017558)

Schein SJ, Colombini M \& Finkelstein A 1976 Reconstitution in planar lipid bilayers of a voltage-dependent anion-selective channel obtained from paramecium mitochondria. Journal of Membrane Biology 30 99-120. (doi:10.1007/BF01869662)

Seli E, Babayev E, Collins SC, Nemeth G \& Horvath TL 2014 Minireview: metabolism of female reproduction: regulatory mechanisms and clinical implications. Molecular Endocrinology 28 790-804. (doi:10.1210/ me.2013-1413)

Sharma U, Conine CC, Shea JM, Boskovic A, Derr AG, Bing XY, Belleannee C, Kucukural A, Serra RW, Sun F et al. 2016 Biogenesis and function of tRNA fragments during sperm maturation and fertilization in mammals. Science 351 391-396. (doi:10.1126/science.aad6780)

Shoshan-Barmatz V, Zakar M, Rosenthal K \& Abu-Hamad S 2009 Key regions of VDAC1 functioning in apoptosis induction and regulation by hexokinase. Biochimica et Biophysica Acta $\mathbf{1 7 8 7}$ 421-430. (doi:10.1016/j.bbabio.2008.11.009)

Solaas K, Legry V, Retterstol K, Berg PR, Holven KB, Ferrieres J, Amouyel P, Lien S, Romeo J, Valtuena J et al. 2010 Suggestive evidence of associations between liver $\mathrm{X}$ receptor beta polymorphisms with type 2 diabetes mellitus and obesity in three cohort studies: HUNT2 (Norway), MONICA (France) and HELENA (Europe). BMC Medical Genetics 11 144. (doi:10.1186/1471-2350-11-144)

Strehler EE \& Zacharias DA 2001 Role of alternative splicing in generating isoform diversity among plasma membrane calcium pumps. Physiological Reviews 81 21-50.

Travis AJ \& Kopf GS 2002 The role of cholesterol efflux in regulating the fertilization potential of mammalian spermatozoa. Journal of Clinical Investigation 110 731-736. (doi:10.1172/JCI0216392)

Visconti PE, Moore GD, Bailey JL, Leclerc P, Connors SA, Pan D, OldsClarke P \& Kopf GS 1995 Capacitation of mouse spermatozoa. II. Protein tyrosine phosphorylation and capacitation are regulated by a cAMP-dependent pathway. Development 121 1139-1150.

Visconti PE, Ning X, Fornes MW, Alvarez JG, Stein P, Connors SA \& Kopf GS 1999 Cholesterol efflux-mediated signal transduction in mammalian sperm: cholesterol release signals an increase in protein tyrosine phosphorylation during mouse sperm capacitation. Developmental Biology 214 429-443. (doi:10.1006/dbio.1999.9428)

Volle DH, Mouzat K, Duggavathi R, Siddeek B, Dechelotte P, Sion B, Veyssiere G, Benahmed M \& Lobaccaro JM 2007 Multiple roles of the nuclear receptors for oxysterols liver $X$ receptor to maintain male fertility. Molecular Endocrinology 21 1014-1027. (doi:10.1210/me.2006-0277)

Wertheimer E, Krapf D, de la Vega-Beltran JL, Sanchez-Cardenas C, Navarrete F, Haddad D, Escoffier J, Salicioni AM, Levin LR, Buck J et al. 2013 Compartmentalization of distinct CAMP signaling pathways in mammalian sperm. Journal of Biological Chemistry 288 35307-35320. (doi:10.1074/jbc.M113.489476)

Whitfield M, Pollet-Villard X, Levy R, Drevet JR \& Saez F 2015 Posttesticular sperm maturation, infertility, and hypercholesterolemia. Asian Journal of Andrology 17 742-748. (doi:10.4103/1008-682X.155536)

Whitfield M, Ouvrier A, Cadet R, Damon-Soubeyrand C, Guiton R, Janny L, Kocer A, Marceau G, Pons-Rejraji H, Trousson A et al. 2016 Liver X Receptors (LXRs) alpha and beta play distinct roles in the mouse epididymis. Biology of Reproduction 94 55. (doi:10.1095/ biolreprod.115.133538)

Received 28July2017

First decision 25August2017

Revised manuscript received 26September2017

Accepted 2October2017 